\title{
Effects of uncertainties in the thermodynamic properties of aerosol components in an air quality model - Part 2: Predictions of the vapour pressures of organic compounds
}

\author{
S. L. Clegg ${ }^{1}$, M. J. Kleeman ${ }^{2}$, R. J. Griffin ${ }^{3}$, and J. H. Seinfeld ${ }^{4}$ \\ ${ }^{1}$ School of Environmental Sciences, University of East Anglia, Norwich NR4 7TJ, UK \\ ${ }^{2}$ Department of Civil and Environmental Engineering, University of California, Davis CA 95616, USA \\ ${ }^{3}$ Institute for the Study of Earth, Oceans and Space, and Department of Earth Sciences, University of New Hampshire, \\ Durham, NH 03824, USA \\ ${ }^{4}$ Department of Chemical Engineering, California Institute of Technology, Pasadena, CA 91125, USA
}

Received: 1 June 2007 - Published in Atmos. Chem. Phys. Discuss.: 26 July 2007

Revised: 14 December 2007 - Accepted: 28 December 2007 - Published: 27 February 2008

\begin{abstract}
Air quality models that generate the concentrations of semi-volatile and other condensable organic compounds using an explicit reaction mechanism require estimates of the vapour pressures of the organic compounds that partition between the aerosol and gas phases. The model of Griffin, Kleeman and co-workers (e.g., Griffin et al., 2005) assumes that aerosol particles consist of an aqueous phase, containing inorganic electrolytes and soluble organic compounds, and a hydrophobic phase containing mainly primary hydrocarbon material. Thirty eight semi-volatile reaction products are grouped into ten surrogate species. In Part 1 of this work (Clegg et al., 2008) the thermodynamic elements of the gas/aerosol partitioning calculation are examined, and the effects of uncertainties and approximations assessed, using a simulation for the South Coast Air Basin around Los Angeles as an example. Here we compare several different methods of predicting vapour pressures of organic compounds, and use the results to determine the likely uncertainties in the vapour pressures of the semi-volatile surrogate species in the model. These are typically an order of magnitude or greater, and are further increased when the fact that each compound represents a range of reaction products (for which vapour pressures can be independently estimated) is taken into account. The effects of the vapour pressure uncertainties associated with the water-soluble semi-volatile species are determined over a wide range of atmospheric liquid water contents. The vapour pressures of the eight primary hydrocarbon surrogate species present in the model, which are
\end{abstract}

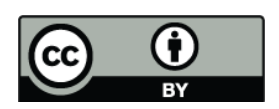

Correspondence to: S. L. Clegg (s.clegg@uea.ac.uk) normally assumed to be involatile, are also predicted. The results suggest that they have vapour pressures high enough to exist in both the aerosol and gas phases under typical atmospheric conditions.

\section{Introduction}

A generalised scheme for including the organic components of aerosols in air quality and other atmospheric models, and used in the UCD-CACM model of Griffin, Kleeman and co-workers (where CACM stands for the Caltech Atmospheric Chemistry Mechanism), is shown in Fig. 1 of Clegg et al. (2008). The partitioning of semi-volatile organic compounds between gas and aerosol phases is driven by their (subcooled) liquid vapour pressures and the associated enthalpies of vaporisation, and their activities in the aqueous and hydrophobic phases, according to the equation:

$p_{i}=x_{i} f_{i} p_{i}^{\circ}$

where $p_{i}^{o}$ is the subcooled liquid vapour pressure of component $i$ at the temperature of interest, and $x_{i}$ is the mole fraction of organic compound $i$ in the aqueous and/or hydrophobic phases. The activity coefficient $f$ is relative to a pure liquid reference state (i.e., $f_{i}=1.0$ when $x_{i}=1.0$ ). Consequently, values of $f_{i}$ for semi-volatile, water soluble, organic solutes in a largely aqueous aerosol will not approximate unity (as would probably be the case if Eq. (1) were formulated using a Henry's law constant) and may have very large values. These need to be taken into account in practical calculations, and in the UCD-CACM model are estimated using UNIFAC.

Published by Copernicus Publications on behalf of the European Geosciences Union. 

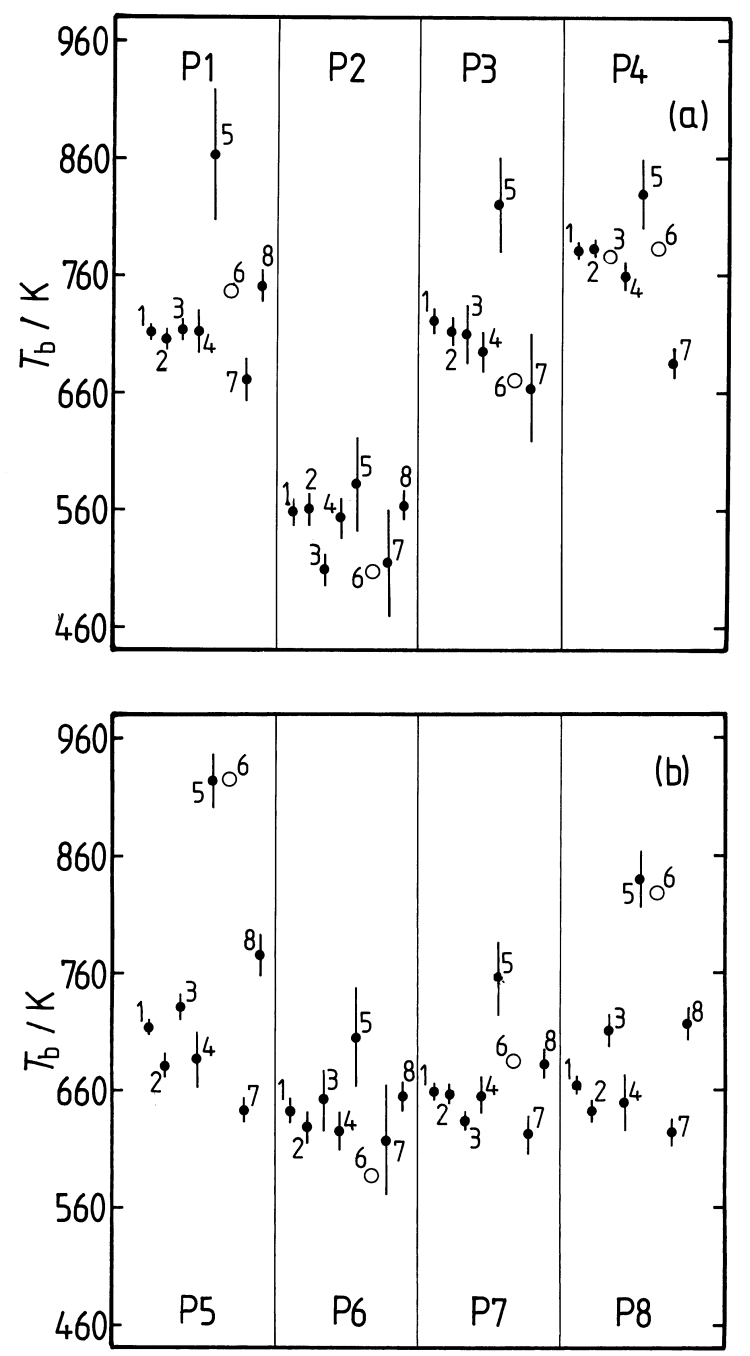

Fig. 1. Boiling points $\left(T_{b}\right)$ of the primary surrogate compounds in the UCD-CACM model, calculated using the following methods: 1 - Nannoolal et al. (2004); 2 - Cordes and Rarey (2002); 3 ACD; 4 - Stein and Brown (1994); 5 - Joback and Reid (1987); 6 Wen and Qiang (2002a, b); 7 - Constantinou and Gani (1994); 8 Marrero-Morejon and Pardillo-Fondevila (1999). The error bars are the DDBST average absolute deviations for the method and compound class to which the surrogate belongs, except for the ACD prediction for which the ACD uncertainty is shown. No DDBST deviations are currently available for predictions shown as open circles.

The thermodynamic properties of even the relatively small number of secondary compounds that have been identified in controlled laboratory experiments (e.g., Yu et al., 1999; Jaoui et al., 2005) have generally not been measured, and must therefore be estimated using structure-based or other methods. In this work, which is a companion paper to that of Clegg et al. (2008), hereafter referred to as Paper 1, we examine uncertainties in predictions of the sub-cooled liquid vapour pressures $p_{i}^{\circ}$ that control the gas/aerosol partitioning of semi-volatile compounds. We also estimate the vapour pressures of the primary surrogate compounds in the UCDCACM model, which are currently assumed to be involatile, because there is evidence that high molecular weight hydrocarbons and other primary emissions are able to partition between gas and aerosol phases (Fraser et al., 1997, 1998).

At least two approaches are possible: the first is to assess predictive methods against reliable data for compounds of a similar molecular weight and functional group composition to those of the secondary organic aerosol (SOA) compounds likely to occur in the atmosphere. The compounds are in many cases the products of oxidation and are likely to be highly polar, containing multiple $-\mathrm{COOH}$ and $-\mathrm{OH}$ groups for example. While such a study is now being carried out (M. Barley, personal communication), and see also Camredon and Aumont (2006), there are very few data for such compounds especially in the sub-cooled liquid state that is thought to apply to atmospheric aerosols. An alternative, complementary, approach which we adopt is to apply current predictive methods to both the surrogate organic compounds in the UCD-CACM model and the reaction products they represent. This enables us (i) to establish approximate ranges of uncertainty of the vapour pressures of compounds present in the model; (ii) to assess the further approximations inherent in grouping multiple compounds into surrogates to which single values of $f_{i}$ and $p_{i}^{\circ}$ are applied and, (iii) to determine (in Paper 1) the significance of uncertainties in terms of gas/aerosol partitioning and SOA formation.

The results are relevant, first, to the general development of atmospheric aerosol models based upon an explicit chemistry and corresponding to Fig. 1 in Paper 1, highlighting particular areas in which a better quantitative understanding of the physical chemistry is needed. Second, they identify elements of the UCD-CACM model on which future work is likely to focus.

\section{The organic compounds and surrogates}

The Caltech Atmospheric Chemistry Mechanism is used to describe the photochemical reactions in the atmosphere including the formation of semi-volatile products leading to the production of secondary organic aerosol. The modelled system consists of 139 gas-phase species participating in 349 chemical reactions, and inorganic ions, gases, and solids (Griffin et al., 2002). For the purpose of calculating gas/aerosol partitioning, the semi-volatile species generated by chemical reaction, and capable of forming SOA, are combined into a set of 10 surrogate species A1-5 and B1-5 (Griffin et al., 2003). We note that the structure of compound B5 (S10 in Fig. 1 of Griffin et al.) has been corrected as described by Griffin et al. (2005), and is shown in Fig. 22 of Paper 1 . There are, in addition, 8 primary organic hydrocarbon surrogate compounds (P1-8). 
Table 1. Variation of Sub-cooled Liquid Vapour Pressure $p^{\circ}(\mathrm{atm})$ at 298.15 K with the Addition of Functional Groups.

\begin{tabular}{llllll}
\hline Hydrocarbon & $p^{\circ}$ & Alcohol & $p^{\circ}$ & Carboxylic acid & $p^{\circ}$ \\
\hline butane & 2.4 & 1-butanol & $8.8 \mathrm{E}-3$ & butanoic acid & $7.74 \mathrm{E}-4$ \\
& & 2-butanol & $2.4 \mathrm{E}-2$ & succinic acid & $4.21 \mathrm{E}-8^{\mathrm{a}}$ \\
& & 1, 2-butanediol & $9.9 \mathrm{E}-5$ & & \\
& & $1,4-$ butanediol & $7.5 \mathrm{E}-6$ & & \\
& 1,3 - butanediol & $4.7 \mathrm{E}-5$ & & \\
& 2,3 - butanediol & $2.4 \mathrm{E}-4$ & & \\
& & &
\end{tabular}

Notes: values of $p^{\circ}$ were taken from the DIPPR Thermophysical Properties Database. ${ }^{\text {a }}$ Estimated for this compound which is primary organic surrogate $\mathrm{P} 2$, see Table 5 .

\section{Vapour pressures}

In the UCD-CACM model, subcooled vapour pressures of secondary organic surrogates A1-5 and B1-5 are estimated by the method of Myrdal and Yalkowsky (1997). This uses the boiling temperature at atmospheric pressure $\left(T_{b}\right)$, the entropy of boiling $\left(\Delta S_{b}\right)$, and the heat capacity change upon boiling $\left(\Delta C_{p}^{(g l)}\right)$. The normal boiling points used in previous applications of the UCD-CACM model were obtained either from measurements or using the estimation software of Advanced Chemistry Developments (ACD) which is described in a manuscript by Kolovanov and Petrauskas (undated $^{1}$ ), (B. L. Hemming, personal communication). Estimates of $\Delta S_{b}$ are obtained from the molecular structure and are expressed in terms of the numbers of torsional bonds ( $\tau$, Eq. (8) of Myrdal and Yalkowsky) and a hydrogen bonding term HBN (their Eq. 9). Values of $\tau$ used previously for some of the SOA surrogate compounds were in error. The correct values of $\tau$ and HBN, used in all calculations in this work, are given for the 8 primary and 10 semi-volatile surrogate compounds in the Appendix. The heat capacity change $\Delta C_{p}^{(g l)}$ is expressed as a function of $\tau$ (Eq. (11) of Myrdal and Yalkowsky). The overall accuracy of the method, assuming that the boiling temperature $T_{b}$ is known, is dependent upon the accuracy of $\Delta S_{b}$ and the assumption that $\Delta C_{p}^{(g l)}$ varies little with temperature. The expressions for $\Delta S_{b}$ and $\Delta C_{p}^{(g l)}$ were obtained by Myrdal and Yalkowsky by fitting to experimental data for 297 compounds. From their Fig. 3 it is apparent that only 19 of the compounds have pressures $<10^{-6}$ atm, 7 below $10^{-8}$ atm, and 2 below $10^{-10}$ atm. For experimental vapour pressures less than $10^{-6}$ atm the residuals in the figure correspond to errors ranging from $\times 2.2$ too high, to too low by about a factor of 5 .

The accuracy of the method for the polar multifunctional compounds of interest to atmospheric chemists, and represented by surrogates here, is hard to establish due to the lack of data. However, it seems certain to be very much

\footnotetext{
${ }^{1}$ Kolovanov, E. and Petrauskas, A.: Towards the maximum accuracy for boiling point prediction, undated manuscript.
}

poorer than the $23 \%$ obtained by Myrdal and Yalkowsky with a test data set of compounds not used in their fit, even without taking into account the fact that the boiling temperatures have to be estimated here. The test data used by Myrdal and Yalkowsky consisted of a group of 19 compounds which, though structurally diverse, are mostly monofunctional. Measured pressures, with one exception, range from $10^{-1.02}$ to $10^{-2.99}$ atmospheres. These values are orders of magnitude greater than those of the semi-volatile compounds of interest in this study. Errors in the vapour pressures predicted by Myrdal and Yalkowsky ranged from 0 to a factor of 2.45 for the test data set.

We note that Zhao et al. (1999) later proposed an alternative expression for the entropy of boiling, and Sangvi and Yalkowsky (2006a) one for the heat capacity change. Neither have so far been evaluated for the prediction of vapour pressures. Our own tests, using data for multifunctional alcohols, suggest that the original HBN term of Myrdal and Yalkowsky (1997) is preferable to the equivalent used in Eq. (5) of Zhao et al. (1999) because, first, the hydrogen bonding effect (which acts to lower vapour pressure) is reduced as molecular mass increases. This is realistic: the effect of an $-\mathrm{OH}$ or $-\mathrm{COOH}$ group on the vapour pressure of a very large molecule, with many carbon atoms, is less than on a small molecule. Second, the effect of adding further polar groups results in a less than linear increase in the hydrogen bonding influence on the predicted entropy of boiling.

The effect of molecular structure and functional group composition on vapour pressure is very important. Table 1 lists vapour pressures for butane and related $\mathrm{C}_{4}$ alcohols and carboxylic acids. The addition of first one, and then two polar functional groups to the butane molecule results in a lowering of $p^{\circ}$ by orders of magnitude. The positions of the groups on the molecule make a large difference, by more than an order of magnitude in some of the examples shown.

In this work we compare estimates of subcooled liquid vapour pressures $p^{\circ}$ and enthalpies of vaporisation $\Delta \mathrm{H}_{\text {vap }}^{o}$ for the semi-volatile surrogate compounds using: (i) the Myrdal and Yalkowsky (1997) method combined with a range of current techniques for predicting the boiling points $T_{b}$, (ii) 
Table 2. Estimated Boiling Temperatures $T_{b}(\mathrm{~K})$, at Atmospheric Pressure, of the Primary Hydrocarbon Surrogates.

\begin{tabular}{llllllllll}
\hline Method & Ref. & P1 & P2 & P3 & P4 & P5 & P6 & P7 & P8 \\
\hline Nannoolal et al. & 1 & 712.0 & 559.4 & 721.5 & 780.8 & 713.0 & 641.3 & 657.8 & 664.2 \\
Cordes and Rarey & 2 & 705.7 & 560.8 & 712.0 & 783.1 & 680.7 & 627.4 & 655.5 & 641.8 \\
ACD & 3 & 714.1 & 509.3 & 710.3 & $774.1^{\mathrm{a}}$ & 730.6 & 651.4 & 632.6 & 709.7 \\
Stein and Brown & 4 & $(712.0)$ & 553.6 & 695.4 & $(759.5)$ & $(685.5)$ & 624.5 & 655.2 & $(648.8)$ \\
Joback and Reid & 5 & {$[863.1]$} & 582.1 & 820.8 & $(829.1)$ & {$[922.7]$} & 705.3 & 757.0 & {$[839.2]$} \\
Wen and Qiang & 6 & {$[746.5]$} & 507.1 & 670.4 & {$[782.7]$} & {$[924.6]$} & 585.6 & 683.4 & {$[826.6]$} \\
Constantinou and Gani & 7 & $(671.1)$ & 515.1 & 663.4 & 685.2 & 642.4 & 616.2 & 621.6 & 623.9 \\
Marrero-Morejon & 8 & $(751.1)$ & 564.2 & - & - & 773.8 & 653.7 & 681.0 & 715.5 \\
Other & & $591^{\mathrm{b}}$ & - & - & - & - & - & - & - \\
ACD (+l-) & 3 & 8 & 13 & 25 & - & 12 & 25 & 5 & 12 \\
\hline
\end{tabular}

Notes: the structures of the molecules are as listed in Fig. 1 of Griffin et al. (2003), with the exception of P5, for which the structure given by Chemical Abstracts for hopane $\left(\mathrm{C}_{30} \mathrm{H}_{52}\right.$, registry number 471-62-5) was used. Values in square brackets [ ] are predictions using methods that are "unrecommended", for the compound class to which the surrogate belongs, by the program Artist (DDBST Software and Separation Technology $\mathrm{GmbH}, 2005$ ) which was used to generate the predictions. Values in parentheses ( ) are similarly listed as "unreliable", and "" indicates that the calculation could not be carried out, for example because of the presence of groups in the molecule whose properties are undefined. The bottom row lists uncertainties $(\mathrm{K})$ associated with the ACD prediction. ${ }^{a}$ Experimental. ${ }^{b}$ DIPPR Thermophysical Properties Database, predicted by staff with a probable error of $<25 \%$. References: 1 - Nannoolal et al. (2004); $2-$ Cordes and Rarey (2002); 3 - Kolovanov and Petrauskas (undated), and ACDLabs software v8.0 (Advanced Chemistry Development Inc., 2004); 4 - Stein and Brown (1994); 5 - Joback and Reid (1987); 6 - Wen and Qiang (2002a, b); 7 - Constantinou and Gani (1994); 8 - Marrero-Morejon and Pardillo-Fontdevila (1999).

the UNIFAC-based method of Asher and Pankow (2006) and Asher et al. (2002), and (iii) the approach of Nannoolal (2007) which is an extension of the boiling point method of Nannoolal et al. (2004). The 8 primary hydrocarbons in the UCD-CACM model (which are currently assumed to be involatile) are included in these comparisons. Vapour pressures calculated for the 38 semi-volatile compounds assigned to the semi-volatile surrogates in the UCD-CACM model are also compared to those for the surrogates themselves. Finally, the effects of uncertainties in the values of $p^{\circ}$ of watersoluble compounds are examined using simple partitioning calculations for a range of atmospheric liquid water contents.

\subsection{Estimation of normal boiling points}

The boiling points of all the surrogate compounds are unknown, with the exception of primary hydrocarbon surrogate P4. Most values used in the UCD-CACM model to date have been estimated using the ACD software package ACDLabs 8.0. Here we compare boiling temperatures $T_{b}$ estimated using eight selected predictive methods, whose characteristics and claimed accuracy are summarised in the Appendix (Nannoolal et al., 2004; Cordes and Rarey, 2002; Wen and Qiang, 2002a, b; Marrero-Morejon and PardilloFontdevila, 1999; Stein and Brown, 1994; Constantinou and Gani, 1994; Joback and Reid, 1987; Advanced Chemistry Developments (Kolovanov and Petrauskas, undated)). The methods are based upon molecular structure. With the exception of the ACD method, all calculations have been carried out using software available from DDBST Software and Separation Technology $\mathrm{GmbH}$. This also provides summaries of the accuracies of the methods, based upon comparisons with all the available normal boiling points in the Dortmund Data Bank. Note that no values are yet available for the method of Wen and Qiang (2002a, b). These summaries are presented as average absolute deviations in $T_{b}$ for each class of compounds (defined in terms of the functional group(s) and types of bonds present) to which the compound of interest belongs. Many molecules, including those considered here, fall into several classes. In these cases we follow the DDBST recommendation and take the largest error listed as being representative, but recognise that for multifunctional compounds the errors for each class to which the compound belongs are likely to be additive to some degree. The ACD method provides an error estimate with each predicted $T_{b}$ value. It is not clear how this is obtained.

Some general comments regarding the boiling point methods can be made: first, the linear relationship employed by Joback and Reid (1987) between the sum of group contributions and boiling point is only valid over a limited range of molecular size - e.g., for molecules with up to about 8 $-\mathrm{CH}_{2}-$ groups in the case of linear alkanes, and up to 15 $-\mathrm{CH}_{2}-$ groups for n-alkanols (Cordes and Rarey, 2002). Second, the effect of polar functional groups such as $-\mathrm{OH}$ and $-\mathrm{COOH}$ on boiling point is not simply additive, as is often assumed in group contribution methods. Of those methods considered here, those of Joback and Reid (1987), Stein 
and Brown (1994), and Wen and Qiang (2002a, b) are essentially additive, whereas that of Constantinou and Gani (1994) is logarithmic, and the method of Marrero-Morejon and Pardillo-Fontdevila (1999) has a dependency on molecular mass. In the equations of Cordes and Rarey (2002) and Nannoolal et al. (2004) the sum of group contributions is divided by a term in the number of atoms in the molecule. The ACD method appears to differ from the others in that predictions use a combination of internal database of boiling points and a structure/fragmentation algorithm.

Estimated boiling points for the primary hydrocarbons are listed in Table 2, and shown in Fig. 1. Many of the estimates of $T_{b}$ disagree by more than would be expected from the average absolute deviations (provided by the DDBST software, as noted above) which are also shown.

The ACD predictions, and those of the methods of Cordes and Rarey (2002) and of Nannoolal et al. (2004), agree within the quoted uncertainties of the methods for surrogates P1, P3, P4 and P6. The earliest method, that of Joback and Reid (1987), yields much higher $T_{b}$ than the other methods in almost all cases. For many of the molecules this is due to the method's known limitations with respect to molecular size, noted above. Values from the method of Wen and Qiang (2002a, b) are also very high for P5 and P8. Excluding the predictions from these two methods, quite large differences are also found for succinic acid (P2) and for poly-substituted decalin (P8). For succinic acid this is not surprising, as these and other prediction methods are generally least satisfactory for multifunctional compounds, particularly those which are small - for which the functional groups are likely to have the greatest influence on physical properties - or for molecules in which the groups are close enough to interact with one another. The vapour pressure $p^{\circ}$ of $\mathrm{P} 2$ (which is representative of dicarboxylic acids in the aerosol) can be estimated independently of the boiling points (see below), and the result suggests that the true boiling point probably lies about midway between the two predictions. In the UCD-CACM model $\mathrm{P} 8$ represents a range of involatile hydrocarbon material found in aerosols, the composition of which is not well understood. The fact that this compound has a boiling point, and an estimated vapour pressure, similar to a number of the other compounds here suggests that the structure chosen for P8 may need to be reconsidered.

If the predictions of the Joback and Reid (1987) method, all values for P8, and a few individual estimates (P5 Marrero-Morejon and Pardillo-Fontdevila; P4 - Constantinou and Gani) are ignored then most values of $T_{b}$ in Table 2 fall within a range of about $75 \mathrm{~K}$ or less. The methods that agree most closely are those of Nannoolal et al. (2004), ACD, and Stein and Brown (1994). (The method of Nannoolal et al. (2004) is a further development of that of Cordes and Rarey (2002), and the two give similar predictions.)

Estimated boiling points for the A and B surrogate compounds, including the values used in the UCD-CACM model code, are shown in Table 3 and in Fig. 2. It is not possible
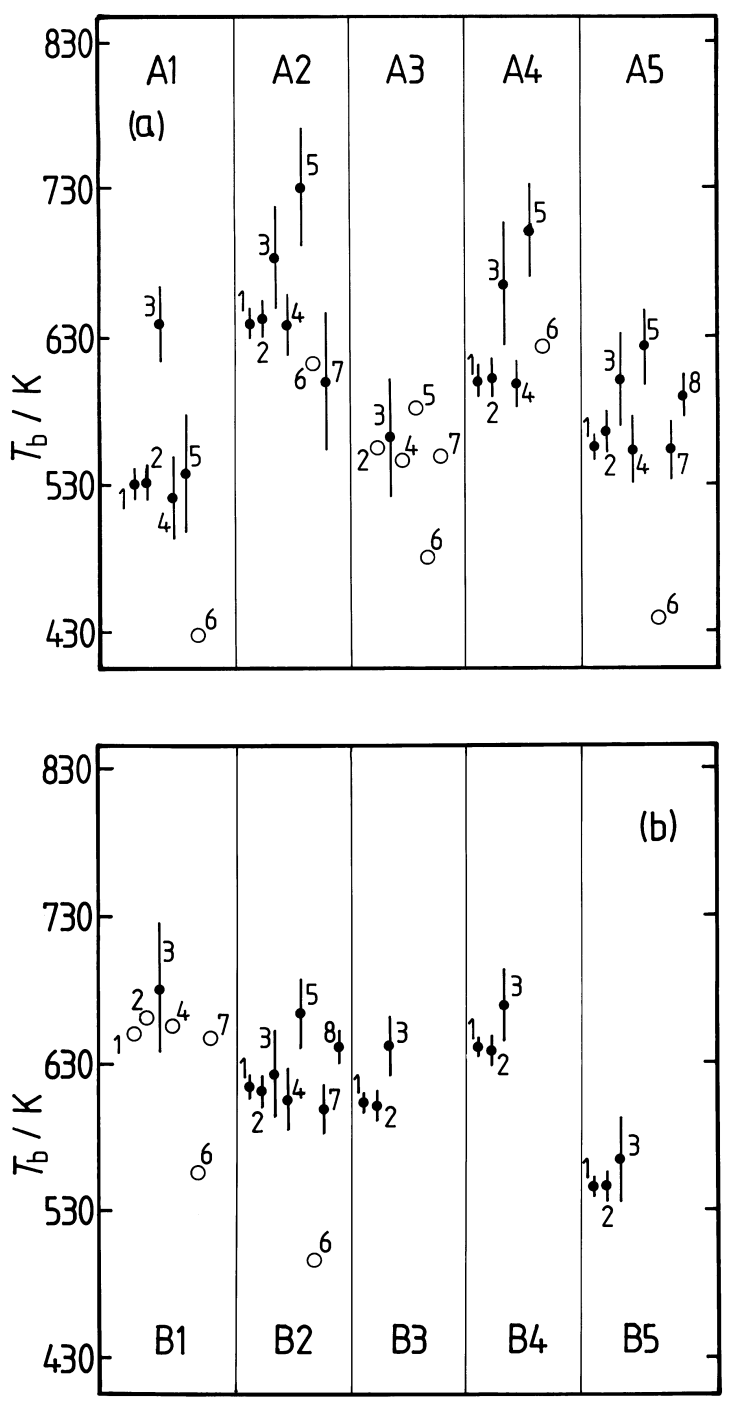

Fig. 2. Boiling points $\left(T_{b}\right)$ of the semi-volatile surrogate compounds in the UCD-CACM model, calculated using the following methods: 1 - Nannoolal et al. (2004); 2 - Cordes and Rarey (2002); 3 - ACD; 4 - Stein and Brown (1994); 5 - Joback and Reid (1987); 6 - Wen and Qiang (2002a, b); 7 - Constantinou and Gani (1994); 8 - Marrero-Morejon and Pardillo-Fondevila (1999). The error bars are the DDBST average absolute deviations for the method and compound class to which the surrogate belongs, except for the ACD prediction for which the ACD uncertainty is shown. No DDBST deviations are currently available for predictions shown as open circles.

to calculate $T_{b}$ for some compounds using some of the methods, notably B3-5 which contain the group $-\mathrm{O}-\mathrm{NO}_{2}$. Nor are DDBST error estimates available for all compounds. The uncertainties associated with the ACD predictive method are significantly greater for these compounds than for the primary surrogates. However, except for A1, A4 and B3 the ACD predictions for the semi-volatile compounds are still consistent with those using the Nannoolal et al. and Stein 
Table 3. Estimated Boiling Temperatures $T_{b}(\mathrm{~K})$, at Atmospheric Pressure, of the Biogenic and Anthropogenic Surrogate Compounds.

\begin{tabular}{llllllllllll}
\hline Method & Ref. & A1 & A2 & A3 & A4 & A5 & B1 & B2 & B3 & B4 & B5 \\
\hline Nannoolal et al. & 1 & 529.6 & 639.5 & - & 598.9 & 553.6 & 651.1 & 614.4 & 603.5 & 641.3 & 546.5 \\
Cordes and Rarey & 2 & 530.5 & 641.5 & 553.6 & 600.8 & 564.7 & 661.4 & 611.5 & 601.0 & 638.8 & 546.5 \\
ACD & 3 & 638.2 & 683.0 & 560.4 & 664.3 & 599.5 & 681.3 & 623.0 & 641.5 & 669.2 & 564.4 \\
Stein and Brown & 4 & 520.1 & 636.7 & 544.6 & 596.3 & 551.9 & 655.8 & 605.8 & - & - & - \\
Joback and Reid & 5 & 536.4 & 730.4 & 580.1 & 700.2 & 621.8 & 825.1 & 664.2 & - & - & - \\
Wen and Qiang & 6 & 425.9 & 610.5 & 478.8 & 621.5 & 437.4 & 556.2 & 496.4 & - & - & - \\
Constantinou and Gani & 7 & - & 598.4 & 547.1 & - & 551.6 & 647.6 & 599.3 & - & - & - \\
Marrero-Morejon & 8 & - & - & - & - & 588.5 & - & 641.2 & - & - & - \\
UCD-CACM model & & 560 & 698 & 575 & 679 & 615 & 685.3 & 634 & 645.5 & 672.5 & 566.3 \\
Other & & 569 & & & & & & & & & \\
ACD (+/-) & 3 & 25 & 35 & 40 & 42 & 32 & 45 & 30 & 21 & 25 & 29 \\
\hline
\end{tabular}

Notes: the structures of the molecules are as listed in Fig. 1 of Griffin et al. (2003), (A1-5 correspond to S1-5, and B1-5 to S6-10), with the exception of B5 (S10) which has been corrected to the structure given in Appendix A of Clegg et al. (2008). Dashes “-” indicate that the calculation could not be carried out, for example because of the presence of groups in the molecule whose properties are undefined. The bottom row lists uncertainties (K) associated with predictions by the ACD method. ${ }^{\text {a }}$ DIPPR Thermophysical Properties Database, predicted by staff with a probable error of $<25 \%$. The numbered references are the same as in Table 2 .

Table 4. The Effect of Errors in the Boiling Temperature $T_{b}(\mathrm{~K})$ on Estimated Vapor Pressures at $298.15 \mathrm{~K}$ for Compounds with Normal Boiling Points from $500 \mathrm{~K}$ to $800 \mathrm{~K}$.

\begin{tabular}{lllll}
\hline$T_{b}$ error & \multicolumn{5}{c}{$p^{\circ} / p^{\circ}$ (base) } \\
& $(500 \mathrm{~K})$ & $(600 \mathrm{~K})$ & $(700 \mathrm{~K})$ & $(800 \mathrm{~K})$ \\
\hline-75 & 56.8 & 70.5 & 88.8 & 105. \\
-50 & 14.1 & 17.5 & 20.2 & 22.6 \\
-20 & 2.93 & 3.17 & 3.36 & 3.50 \\
-10 & 1.72 & 1.78 & 1.83 & 1.87 \\
0 & 1.0 & 1.0 & 1.0 & 1.0 \\
10 & 0.580 & 0.559 & 0.544 & 0.533 \\
20 & 0.335 & 0.311 & 0.295 & 0.284 \\
50 & 0.063 & 0.0529 & 0.0466 & 0.0423 \\
75 & 0.015 & 0.0118 & 0.0099 & 0.0086 \\
\hline
\end{tabular}

Notes: $p^{\circ}$ (base) is the vapour pressure calculated at the listed boiling point using the Myrdal and Yalkowsky (1997) equation, and $p^{\circ}$ is the value of the vapour pressure calculated for the listed boiling point $+T_{b}$ error. Thus, for example, an estimate of $T_{b}$ that is $75 \mathrm{~K}$ too low for a compound with a true boiling point of $500 \mathrm{~K}$ will yield a vapour pressure that is too high by a factor of 56.8 .

and Brown methods. For surrogates A1, A2, A4, A5 and B3 the values of $T_{b}$ obtained using the ACD method, and that of Nannoolal et al., differ by amounts ranging from $9 \mathrm{~K}$ to over $100 \mathrm{~K}$ with the ACD predictions always higher.

The general influence of errors in the predicted $T_{b}$ on calculations of $p^{\circ}$ at $298.15 \mathrm{~K}$ using the Myrdal and Yalkowsky (1987) equation is illustrated in Table 4. This lists the ratio of the predicted $p^{\circ}$ to the base $p^{\circ}$ (i.e., the value calculated using the Myrdal and Yalkowsky equation for the $T_{b}$ above each column) for assumed errors in $T_{b}$ ranging from $-75 \mathrm{~K}$ to $+75 \mathrm{~K}$. It can be seen that there is a dependence of the ratio on $T_{b}$ for large errors. Variations in predicted $T_{b}$ over ranges of $20 \mathrm{~K}$ to $50 \mathrm{~K}$ are typical for both primary and semivolatile surrogate compounds, even ignoring the predicted $T_{b}$ that deviate most. The error estimates for the ACD predictions range from $\pm 5 \mathrm{~K}$ to $\pm 45 \mathrm{~K}$, see Tables 2 and 3 , and while they are the most conservative they also appear to be the most realistic. The results in Table 4 show that these uncertainties are likely to result in calculated $p^{\circ}$ which are incorrect by factors of about $\times 1.4$ to $\times 20$, without taking into account additional errors associated with the use of the Myrdal and Yalkowsky equation. It will be seen in the following section that values of $p^{\circ}$ based on $T_{b}$ estimated by the methods considered here do indeed differ by similar or larger factors.

\subsection{Predicted vapour pressures}

Estimated pure compound vapour pressures at $298.15 \mathrm{~K}$ for surrogate primary compounds P1 to P8 are shown in Table 5. The methods used are the Myrdal and Yalkowsky model with boiling points from Nannoolal et al. (2004), ACD including values based upon the upper and lower uncertainty limits of the predicted $T_{b}$, the UNIFAC based method of Asher and co-workers, and a recently completed extension of the boiling point method of Nannoolal et al. (2004) to predict $p^{\circ}$. All compounds have vapour pressures below the lower limit of validity of the ACD vapour pressure prediction model $(0.001 \mathrm{~mm} \mathrm{Hg})$ in the ACDLabs software, and therefore that method is not used. 
Table 5. Estimated Vapour Pressures $p^{\circ}(\mathrm{atm})$ and Enthalpies of Vaporisation $\Delta H_{\mathrm{vap}}^{o}\left(\mathrm{~kJ} \mathrm{~mol}^{-1}\right)$ of Primary Hydrocarbon Surrogate Species as Supercooled Liquids at $298.15 \mathrm{~K}$.

\begin{tabular}{|c|c|c|c|c|c|c|c|c|c|}
\hline \multirow[b]{2}{*}{ Method } & \multirow[t]{2}{*}{ Ref. } & \multicolumn{2}{|c|}{ P1 } & \multicolumn{2}{|c|}{$\mathrm{P} 2$} & \multicolumn{2}{|c|}{ P3 } & \multicolumn{2}{|c|}{ P4 } \\
\hline & & $p^{\circ}$ & $\Delta H_{\text {vap }}^{o}$ & $p^{\circ}$ & $\Delta H_{\text {vap }}^{o}$ & $p^{\circ}$ & $\Delta H_{\text {vap }}^{o}$ & $p^{\circ}$ & $\Delta H_{\mathrm{vap}}^{o}$ \\
\hline Nannoolal & 1 & $1.82 \mathrm{E}-11$ & $131.6^{6}$ & $4.65 \mathrm{E}-7$ & 88.5 & $3.17 \mathrm{E}-13$ & $152.5^{1}$ & $3.61 \mathrm{E}-12$ & 137.4 \\
\hline Asher & 2 & $2.55 \mathrm{E}-15$ & 232.2 & $8.12 \mathrm{E}-8$ & 88.7 & $9.04 \mathrm{E}-16$ & 194.9 & $8.00 \mathrm{E}-13$ & 154.5 \\
\hline Nannoolal et al. & 3 & $1.26 \mathrm{E}-11$ & 128.5 & $1.08 \mathrm{E}-6$ & 82.7 & $2.33 \mathrm{E}-10$ & 107.5 & $4.41 \mathrm{E}-11$ & 110.6 \\
\hline $\mathrm{ACD}$ & 4 & $1.08 \mathrm{E}-11(1.8)$ & 129.0 & $2.03 \mathrm{E}-5(2.1)$ & 72.8 & $4.56 \mathrm{E}-10(4.5)$ & 105.4 & $6.45 \mathrm{E}-11^{\mathrm{a}}$ & 109.4 \\
\hline $\mathrm{ACD}$ (+ error) & 5 & $6.04 \mathrm{E}-12$ & & $9.58 \mathrm{E}-6$ & & $1.02 \mathrm{E}-10$ & & - & \\
\hline $\mathrm{ACD}$ (- error) & 6 & $1.94 \mathrm{E}-11$ & & $4.29 \mathrm{E}-5$ & & $2.02 \mathrm{E}-9$ & & - & \\
\hline \multirow[t]{2}{*}{ Experimental } & & & & $4.21 \mathrm{E}-8(4.0)^{\mathrm{b}}$ & & & & $4.22 \mathrm{E}-12^{\mathrm{c}}$ & \\
\hline & Ref. & $\mathrm{Ps}$ & & & & $\mathrm{P}^{\prime}$ & & P8 & \\
\hline Method & & $p^{\circ}$ & $\Delta H_{\text {vap }}^{o}$ & $p^{\circ}$ & $\Delta H_{\text {vap }}^{o}$ & $p^{\circ}$ & $\Delta H_{\text {vap }}^{o}$ & $p^{\circ}$ & $\Delta H_{\text {vap }}^{o}$ \\
\hline Nannoolal & 1 & $9.47 \mathrm{E}-10$ & 110.5 & $6.54 \mathrm{E}-10$ & 117.2 & $1.56 \mathrm{E}-10$ & 123.7 & 8.063E-8 & 89.1 \\
\hline Asher & 2 & $2.60 \mathrm{E}-12$ & 182.2 & $4.23 \mathrm{E}-10$ & 118.5 & $1.31 \mathrm{E}-11$ & 170.4 & $2.45 \mathrm{E}-10$ & 132.5 \\
\hline Nannoolal et al. & 3 & $1.83 \mathrm{E}-9$ & 99.2 & $1.81 \mathrm{E}-8$ & 94.3 & $1.66 \mathrm{E}-9$ & 108.0 & $1.20 \mathrm{E}-8$ & 95.7 \\
\hline $\mathrm{ACD}$ & 4 & $6.82 \mathrm{E}-10(2.0)$ & 102.4 & $9.98 \mathrm{E}-9(4.5)$ & 96.2 & $8.71 \mathrm{E}-9(1.4)$ & 102.5 & $8.30 \mathrm{E}-10(2.0)$ & 104.5 \\
\hline $\mathrm{ACD}$ (+ error) & 5 & $3.46 \mathrm{E}-10$ & & $2.23 \mathrm{E}-09$ & & $6.28 \mathrm{E}-09$ & & $4.06 \mathrm{E}-10$ & \\
\hline $\mathrm{ACD}$ (- error) & 6 & $1.34 \mathrm{E}-09$ & & 4.39E-08 & & $1.21 \mathrm{E}-08$ & & $1.69 \mathrm{E}-09$ & \\
\hline
\end{tabular}

Notes: numbers in parentheses following the ACD $p^{\circ}$ are the factors by which $p^{\circ}$ is increased and decreased if the upper and lower bounds on the estimated $T_{b}$ are assumed. ${ }^{a}$ Based on an experimental boiling point from an unknown source, quoted by the ACD software, hence there is no error estimated. ${ }^{b}$ Based on the vapour pressure of the solid acid, its aquous solubility and activity coefficient calculated using UNIFAC, but using modified parameters presented by Peng et al. (2001). The value in parentheses is the factor by which the estimated vapor pressure is altered if standard UNIFAC parameters are used. ${ }^{\mathrm{c}}$ Lei et al. (2002). References: 1 - Nannoolal (2007) (the method is based upon that of Nannoolal et al. (2004) for $T_{b}$ ); 2 - Asher and Pankow (2006), and Asher et al. (2002); 3 - Myrdal and Yalkowsky (1997) equation, with $T_{b}$ from Nannoolal et al. (2004); 4 - Myrdal and Yalkowsky (1997) equation, with $T_{b}$ calculated using the ACD software; $5-$ as for 4 , except that the uncertainty $\mathrm{ACD}(+/-)$ from Table 2 is added to $T_{b} ; 6-$ as for 4 , except that the uncertainty ACD (+/-) from Table 2 is subtracted from $T_{b}$.

We have included in Table 5 a value of $p^{\circ}$ for succinic acid (P2) derived from the vapour pressure of the solid (Ribeiro da Silva et al., 2001), its activity product in water (see Clegg and Seinfeld, 2006) and estimates of its activity coefficient from UNIFAC. For P4 an experimental value based upon gas chromatographic retention time was obtained (Lei et al., 2002). Upper and lower limits for $p^{\circ}$, based upon the uncertainty in the ACD estimate of $T_{b}$, are listed in the table and are also expressed in terms of an error factor in parentheses. Thus the Myrdal and Yalkowsky equation, using the ACD $T_{b}=714.1 \mathrm{~K}$ for $\mathrm{P} 1$, yields a $p^{\circ}$ of $1.08 \times 10^{-11}$ atm for the supercooled liquid at $298.15 \mathrm{~K}$. Adding the uncertainty limit of $\pm 8 \mathrm{~K}$ (Table 2 ), to obtain $T_{b}=722.1 \mathrm{~K}$ and $T_{b}=706.1 \mathrm{~K}$, yields $p^{\circ}$ values that differ by a factor of 1.8 from the base prediction.

The Nannoolal (2007) vapour pressure model, and the Myrdal and Yalkowsky method with the ACD and Nannoolal et al. (2004) estimates of $T_{b}$, agree best for hydrocarbons P1, P5 and P8. In most cases the predictions of the UNIFACbased approach are lower, in some instances by orders of magnitude. For P4 the experimentally determined vapour pressure agrees fairly closely with the result from the Nannoolal vapour pressure model, and to within an order of magnitude with the Myrdal and Yalkowsky prediction based upon the experimental boiling point.
The value of $p^{\circ}$ estimated for succinic acid (P2) from the solubility of the solid in water and its vapour pressure (see Table 5) is lower than all the other values except that from the model of Asher (Asher and Pankow, 2006). This acid was included in the data set they used for fitting their model. We also note that the Myrdal and Yalkowsky method, using an estimated $T_{b}$ of $591 \mathrm{~K}$ from the DIPPR Thermophysical Properties Database, yields $p^{\circ}$ equal to $1.61 \times 10^{-7}$ atm at $298.15 \mathrm{~K}$. This agrees reasonably well with the value based upon the vapour pressure of the solid. It is unclear which of the many estimates of $p^{\circ}$ is more nearly correct.

Estimated $p^{\circ}$ and values of $\Delta H_{\text {vap }}^{o}$ for the surrogate compounds treated as semi-volatile in the UCD-CACM model are shown in Tables 6 and 7. For oxalic acid (A1) there is also an estimate based upon the Henry's law constant (Clegg et al., 1996), and a further value based on a predicted $T_{b}$ taken from the DIPPR Thermophysical Properties Database. The vapour pressures, with the exception of the prediction based upon the ACD boiling point, range between about $2 \times 10^{-7}$ to $5 \times 10^{-6} \mathrm{~atm}$ and agree reasonably well. Previous work has suggested that oxalic acid will partition in the atmosphere such that significant amounts can occur in both the aerosol and gas phases, dependent upon atmospheric conditions (Clegg et al., 1996). The UNIFAC-based method is 
Table 6. Estimated Vapour Pressures of Vapour Pressures $p^{\circ}(\mathrm{atm})$ and Enthalpies of Vaporisation $\Delta H_{\mathrm{vap}}^{o}\left(\mathrm{~kJ}\right.$ mol $\left.{ }^{-1}\right)$ of Semi-Volatile Surrogate Species as Supercooled Liquids at 298.15 K.

\begin{tabular}{|c|c|c|c|c|c|c|c|c|c|c|c|}
\hline \multirow[b]{2}{*}{ Method } & \multirow[b]{2}{*}{ Ref. } & \multicolumn{2}{|c|}{ A1 } & \multicolumn{2}{|c|}{ A2 } & \multicolumn{2}{|c|}{ A3 } & \multicolumn{2}{|c|}{ A4 } & \multicolumn{2}{|c|}{ A5 } \\
\hline & & $p^{\circ}$ & $\Delta H_{\mathrm{vap}}^{o}$ & $p^{\circ}$ & $\Delta H_{\mathrm{vap}}^{o}$ & $p^{\circ}$ & $\Delta H_{\text {vap }}^{o}$ & $p^{\circ}$ & $\Delta H_{\text {vap }}^{o}$ & $p^{\circ}$ & $\Delta H_{\text {vap }}^{o}$ \\
\hline $\begin{array}{l}\text { UCD-CACM } \\
\text { model }\end{array}$ & & $7.34 \mathrm{E}-7$ & 84.2 & $5.02 \mathrm{E}-10$ & 106.4 & $1.01 \mathrm{E}-6$ & 81.3 & $1.50 \mathrm{E}-9$ & 103.2 & $8.19 \mathrm{E}-8$ & 90.7 \\
\hline Asher & 2 & $2.87 \mathrm{E}-7$ & 73.0 & 4.47E-11 & 140.5 & $1.64 \mathrm{E}-7$ & 116.9 & $1.15 \mathrm{E}-8$ & 115.0 & $1.51 \mathrm{E}-6$ & 106.3 \\
\hline Nannoolal et al. & 3 & $4.56 \mathrm{E}-6$ & 78.2 & $1.76 \mathrm{E}-8$ & 95.1 & - & - & $1.87 \mathrm{E}-7$ & 87.6 & $2.95 \mathrm{E}-6$ & 78.6 \\
\hline $\mathrm{ACD}$ & 4 & $\begin{array}{l}5.80 \mathrm{E}-9 \\
(4.9)\end{array}$ & & $\begin{array}{l}1.26 \mathrm{E}-9 \\
(8.6)\end{array}$ & & $\begin{array}{l}2.32 \mathrm{E} 6 \\
(9.9)\end{array}$ & & $\begin{array}{l}3.69 \mathrm{E}-9 \\
(13.2)\end{array}$ & 100.4 & $\begin{array}{l}2.05 \mathrm{E}-7 \\
(6.7)\end{array}$ & 87.6 \\
\hline $\mathrm{ACD}$ (+ error) & 5 & $1.19 \mathrm{E}-9$ & 104.7 & $1.05 \mathrm{E}-8$ & 96.8 & $2.16 \mathrm{E}-5$ & 70.9 & $4.66 \mathrm{E}-8$ & 92.2 & $1.33 \mathrm{E}-6$ & 81.3 \\
\hline $\mathrm{ACD}$ (- error) & 6 & $2.78 \mathrm{E}-8$ & 94.8 & $1.46 \mathrm{E}-10$ & 110.3 & $2.35 \mathrm{E}-7$ & 86.1 & $2.79 \mathrm{E}-10$ & 108.5 & $3.06 \mathrm{E}-8$ & 93.9 \\
\hline DIPPR & 7 & $4.25 \mathrm{E}-7$ & 86.0 & & & & & & & & \\
\hline Other & & $2.62 \mathrm{E}-7^{\mathrm{a}}$ & 78.9 & & & $3.47 \mathrm{E}-6$ & $77.2^{\mathrm{b}}$ & & & & \\
\hline
\end{tabular}

Notes: numbers in parentheses following ACD $p^{\circ}$ are the factors by which $p^{\circ}$ is increased and decreased if the upper and lower bounds on the estimated $T_{b}$ are assumed. ${ }^{\text {a }}$ Based on a Henry's law constant from Clegg et al. (1996), and UNIFAC using modified values of parameters determined by Peng et al. (2001). Alternatively, $p^{\circ}=7.67 \times 10^{-8}$ atm is obtained assuming Raoult's law behavior of the undissociated molecule, and $6.53 \times 10^{-8}$ atm using UNIFAC with unmodified parameters to calculate the activity coefficient of the acid. Dissociation is taken into account in these calculations. ${ }^{b}$ Myrdal and Yalkowsky (1997) equation, with $T_{b}$ from Cordes and Rarey (2002). References: 1 - Nannoolal (2007); 2 - Asher and Pankow (2006), and Asher et al. (2002); 3 - Myrdal and Yalkowsky (1997) equation, with $T_{b}$ from Nannoolal et al. (2004); 4 - Myrdal and Yalkowsky (1997) equation, with $T_{b}$ calculated using the ACD software; 5 - as for 4, except that the uncertainty ACD (+/-) from Table 3 is added to $T_{b} ; 6$ - as for 4, except that the uncertainty ACD (+/-) from Table 3 is subtracted from $T_{b}$; 7 - Mydral and Yalkowsy (1997) equation, with $T_{b}$ from the DIPPR Thermophysical Database.

Table 7. Estimated Vapor Pressures of Vapor Pressures $p^{\circ}$ (atm) and Enthalpies of Vaporisation $\Delta H_{\mathrm{vap}}^{o}\left(\mathrm{~kJ} \mathrm{~mol}^{-1}\right)$ of Semi-Volatile Surrogate Species as Supercooled Liquids at $298.15 \mathrm{~K}$.

\begin{tabular}{|c|c|c|c|c|c|c|c|c|c|c|c|}
\hline \multirow[b]{2}{*}{ Method } & \multirow[b]{2}{*}{ Ref. } & \multicolumn{2}{|c|}{ B1 } & \multicolumn{2}{|c|}{ B2 } & \multicolumn{2}{|c|}{ B3 } & \multicolumn{2}{|c|}{ B4 } & \multicolumn{2}{|c|}{ B5 } \\
\hline & & $p^{\circ}$ & $\Delta H_{\mathrm{vap}}^{o}$ & $p^{\circ}$ & $\Delta H_{\text {vap }}^{o}$ & $p^{\circ}$ & $\Delta H_{\text {vap }}^{o}$ & $p^{\circ}$ & $\Delta H_{\mathrm{vap}}^{o}$ & $p^{\circ}$ & $\Delta H_{\mathrm{vap}}^{o}$ \\
\hline $\begin{array}{l}\text { UCD-CACM } \\
\text { model }\end{array}$ & & $1.14 \mathrm{E}-9$ & 104.1 & $3.64 \mathrm{E}-8$ & 95.2 & $3.29 \mathrm{E}-8$ & 92.7 & $9.22 \mathrm{E}-10$ & 108.9 & $2.47 \mathrm{E}-6$ & 77.3 \\
\hline Nannoolal & 1 & $1.22 \mathrm{E}-10$ & 125.6 & $1.01 \mathrm{E}-8$ & 104.5 & $1.42 \mathrm{E}-7$ & 90.5 & $3.05 \mathrm{E}-10$ & 121.5 & $1.38 \mathrm{E}-6$ & 83.7 \\
\hline Asher & 2 & - & - & $1.04 \mathrm{E}-8$ & 111.3 & - & - & - & - & - & - \\
\hline Nannoolal et al. & 3 & $1.59 \mathrm{E}-8$ & 93.9 & $1.61 \mathrm{E}-7$ & 86.2 & $6.13 \mathrm{E}-7$ & 81.1 & $6.00 \mathrm{E}-9$ & 103.2 & $6.95 \mathrm{E}-6$ & 74.2 \\
\hline $\mathrm{ACD}$ & 4 & $\begin{array}{l}2.70 \mathrm{E}-9 \\
(14.0)\end{array}$ & 99.6 & $\begin{array}{l}9.87 \mathrm{E}-8 \\
(5.5)\end{array}$ & 87.8 & $\begin{array}{l}7.63 \mathrm{E}-8 \\
(3.2)\end{array}$ & 88.0 & $\begin{array}{l}9.65 \mathrm{E}-10 \\
(5.2)\end{array}$ & 109.3 & $\begin{array}{l}2.46 \mathrm{E}-6 \\
(5.0)\end{array}$ & 77.9 \\
\hline $\mathrm{ACD}$ (+ error) & 5 & $3.74 \mathrm{E}-8$ & 91.2 & $5.36 \mathrm{E}-7$ & 82.3 & $2.42 \mathrm{E}-7$ & 84.2 & 4.95E-9 & 103.8 & $1.22 \mathrm{E}-5$ & 72.3 \\
\hline $\mathrm{ACD}$ (- error) & 6 & $1.86 \mathrm{E}-10$ & 107.9 & $1.77 \mathrm{E}-8$ & 93.3 & $2.37 \mathrm{E}-8$ & 91.8 & $1.84 \mathrm{E}-10$ & 114.7 & $4.85 \mathrm{E}-7$ & 83.2 \\
\hline
\end{tabular}

Notes: numbers in parentheses following the ACD $p^{\circ}$ are the factors by which $p^{\circ}$ is increased and decreased if the upper and lower bounds on the estimated $T_{b}$ are assumed. References: 1 - Nannoolal (2007); 2 - Asher and Pankow (2006), and Asher et al. (2002); 3 - Myrdal and Yalkowsky (1997) equation, with $T_{b}$ from Nannoolal et al. (2004); 4 - Myrdal and Yalkowsky (1997) equation, with $T_{b}$ calculated using the ACD software; 5 - as for 4, except that the uncertainty ACD (+ error) from Table 3 is added to $T_{b} ; 6$ - as for 4 , except that the uncertainty ACD (- error) from Table 3 is subtracted from $T_{b}$.

not applicable to most of surrogates B1-5 because not all of the required structural groups are defined. It also yields enthalpies of vaporization that are consistently greater than the other approaches.
Camredon and Aumont (2006) have assessed four structure-activity relationships for estimating $p^{\circ}$ against a database of experimental values. The methods assessed include both the UNIFAC-based approach of Asher and coworkers, and also the Myrdal and Yalkowsky (1997) equation combined with the boiling point equation of Joback and Reid (1987) which we have found yields significantly higher $T_{b}$ 
Table 8. Subcooled Liquid Vapour Pressures $p^{\circ}(\mathrm{atm})$ of the Component Compounds of the Semi-Volatile Surrogate Species at $298.15 \mathrm{~K}$.

\begin{tabular}{lllll}
\hline Surrogate & No. compounds & $p^{\circ}$ range $^{\mathrm{a}}$ & ratio $^{\mathrm{b}}$ & $p^{\circ}$ (surrogate) \\
\hline B1 & 3 & $5.7 \mathrm{E}-10-6.6 \mathrm{E}-5$ & $1.1 \mathrm{E} 5$ & $1.22 \mathrm{E}-10$ \\
B2 & 8 & $3.6 \mathrm{E}-8-2.3 \mathrm{E}-4$ & 6400 & $1.01 \mathrm{E}-8$ \\
B3 & 4 & $1.4 \mathrm{E}-5-2.5 \mathrm{E}-4$ & 18.0 & $1.42 \mathrm{E}-7$ \\
B4 & 4 & $3.1 \mathrm{E}-8-5.1 \mathrm{E}-5$ & 1600 & $3.05 \mathrm{E}-10$ \\
B5 & 4 & $8.7 \mathrm{E}-7-1.7 \mathrm{E}-3$ & 1900 & $1.38 \mathrm{E}-6$ \\
A1 & 2 & $6.4 \mathrm{E}-4-4.3 \mathrm{E}-3$ & 6.7 & $6.37 \mathrm{E}-6$ \\
A2 & 6 & $2.6 \mathrm{E}-10-1.4 \mathrm{E}-4^{\mathrm{c}}$ & $5.3 \mathrm{E} 5$ & $2.81 \mathrm{E}-10$ \\
A3 & 2 & $1.3 \mathrm{E}-4^{\mathrm{d}}$ & $\mathrm{d}$ & d \\
A4 & 3 & $3.3 \mathrm{E}-7-4.3 \mathrm{E}-5$ & 130 & $1.12 \mathrm{E}-8$ \\
A5 & 2 & $8.6 \mathrm{E}-5-9.3 \mathrm{E}-3$ & 110 & $1.38 \mathrm{E}-6$ \\
\hline
\end{tabular}

Notes: the method of Nannoolal (2007) was used to calculate the results above. The assignment of reaction products to surrogate species in the UCD-CACM model is as follows: B1=AP1+AP6+UR31; B2=ADAC+RPR7+RP14+RP19+UR2+UR14+UR27+ARAC; $\mathrm{B} 3=\mathrm{AP} 10+\mathrm{UR} 11+\mathrm{UR} 15+\mathrm{UR} 19 ; \quad \mathrm{B} 4=\mathrm{AP} 11+\mathrm{AP} 12+\mathrm{UR} 20+\mathrm{UR} 34 ; \quad \mathrm{B} 5=\mathrm{AP} 7+\mathrm{AP} 8+\mathrm{UR} 5+\mathrm{UR} 6 ; \quad$ A1=UR21+UR28; A2=RP13+RP17+RP18+UR26+UR29+UR30; A3=RPR9+RP12; A4=UR3+UR8+UR23; A5=UR7+UR17, see Griffin et al. (2002). a The largest and smallest vapour pressures of the components assigned to the surrogate species. ${ }^{b}$ The value of the largest vapour pressure in the previous column, divided by the smallest. ${ }^{c}$ Vapour pressures of components RP17 and UR29 cannot be calculated using this method. $\mathrm{d}$ The vapour pressure RPR9 cannot be calculated using this method.

than other methods (Figs. 1 and 2). Camredon and Aumont conclude that these two methods of estimating $p^{\circ}$ were the most reliable for compounds with low vapour pressures, although they also found that values of $p^{\circ}$ predicted using the different methods could vary by factors of greater than 100 . These findings are broadly consistent with our results, although our calculations and the work of Stein and Brown (1994) suggests that the equation of Joback and Reid does not yield the most accurate predictions of $T_{b}$. This is also noted by Camredon and Aumont, who did not use the work of Stein and Brown as it was based upon many of the same data used in their assessment.

The range of vapour pressures obtained by the different methods, and shown in Tables 5 to 7 , exceed by a significant margin what would be expected from the uncertainties associated with each boiling point estimation and vapour pressure prediction method. This must be due partly to the fact that the models are fitted to data for generally much simpler molecules than those of interest here, which also have higher vapour pressures (lower boiling points). The ranges of the calculated vapour pressures in the tables, as ratios $p^{\circ}$ (highest) $/ p^{\circ}$ (lowest), are: $7.1 \times 10^{3}$ [1.7] (P1), 482 [44] $(\mathrm{P} 2), 5.0 \times 10^{5}\left[1.4 \times 10^{3}\right](\mathrm{P} 3), 80$ [18] (P4), 704 [2.7] (P5), 43 [43] (P6), 665 [56] (P7), 329 [329] (P8), 1098 [1098] (A1), 393 [63] (A2), 21 [2.3] (A3), 125 [125] (A4), 36 [36] (A5), 130 [-] (B1), 16 [16] (B2), 19 [-] (B3), 20 [-] (B4) and 5.0 [-] (B5). The values in square brackets are ratios which omit predictions of the UNIFAC-based method of Asher, and are in many cases smaller. However, it is unclear whether the greater consistency of the predictions of the other methods is because of higher accuracy or because of their similarity (being based upon boiling points). The ranges of pre- dicted vapour pressures obtained using the various methods are comparable for both primary and secondary compounds, if the UNIFAC-based predictions are omitted, although the uncertainties yielded by the ACD method (and listed in the tables) are lower for the primary compounds P1-P8 as would be expected.

The use of surrogate compounds allows gas/aerosol partitioning of the potentially large number of semi-volatile products of gas phase reactions to be handled efficiently in atmospheric calculations. However, key properties - including vapour pressure - of the individual compounds making up each surrogate can also be evaluated, and should probably be used in their assignment. Table 8 summarises the results of vapour pressure predictions for the 38 semi-volatile reaction products that make up surrogate compounds A1-5 and B1-5 in the UCD-CACM model, expressed as the range of calculated partial pressures of the component compounds assigned to each surrogate, and the estimated vapour pressures of the surrogates themselves. The ranges vary from about a factor of 10 (i.e., the highest component vapour pressure divided by the smallest) to as much as $10^{5}$. For some of the surrogate compounds the estimated vapour pressures lie outside the ranges of $p^{\circ}$ of the component compounds, for the method used in the calculations. This is clearly an important problem, and the assignment of surrogate species and their properties needs to be considered carefully in the development of atmospheric models. It may be best to assign the $p^{\circ}$ of the surrogate species based simply upon averages of the estimates for the component compounds, giving weight to those that are atmospherically most important.

Based on above comparisons, the vapour pressures of the semi-volatile surrogate compounds are uncertain by an order 

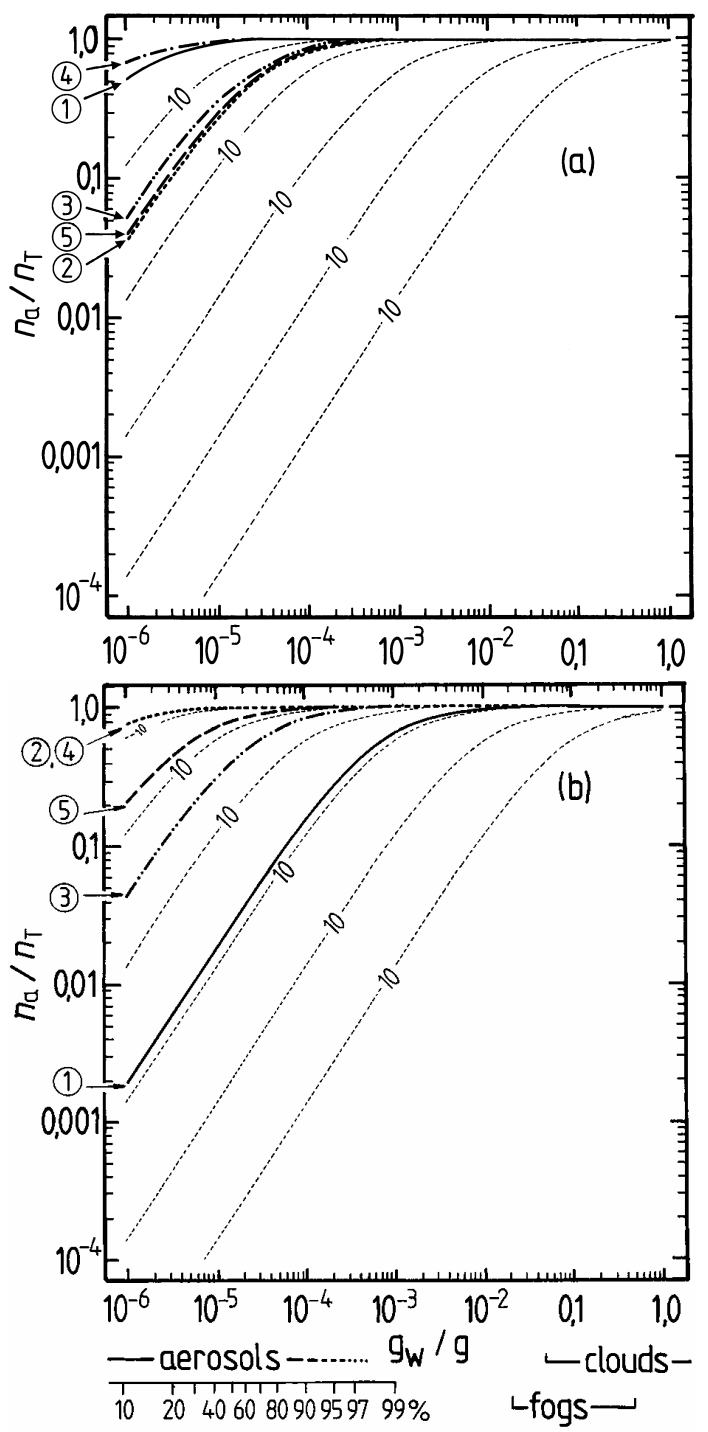

Fig. 3. Fractions of the semi-volatile surrogate compounds present in the aerosol phase, calculated using Eq. (2a), plotted against atmospheric liquid water content $\left(g_{w} / \mathrm{g} \mathrm{m}^{-3}\right)$ for $T=298.15 \mathrm{~K}$. Solubility in water and unit activity coefficients are assumed, and the values of $p_{i}^{\circ}$ are those used in the UCD-CACM model, including the downward adjustments to account for the effects of chemical reactions. The thin dashed lines represent the calculated partitioning at intervals of factors of 10 in $f_{i} p_{i}^{\circ}$. (a) Lines - surrogate species B1-5, indicated by the circled numbers on the y-axis; (b) lines - surrogate species A1-5. Approximate ranges of atmospheric liquid water content associated with clouds, fogs and aerosols (including typical $\mathrm{RH}$ based on $10^{-4} \mathrm{~g} \mathrm{~m}^{-3}$ of aerosol water at $90 \% \mathrm{RH}$, and an acid ammonium sulphate aerosol) are indicated.

of magnitude or greater in most cases. Vapour pressures are very sensitive to the types, numbers, and positions of the functional groups present. Consequently, the estimated vapour pressures of the compounds making up the surrogates cover very wide ranges, as shown in Table 8 . In the UCDCACM model the vapour pressures of several surrogate compounds have been adjusted, based upon chamber measurements of SOA formation as described by Griffin et al. (2005). This is likely to be necessary for other atmospheric models of the same type, given that predictive methods for vapour pressures of polar multifunctional compounds yield values that are subject to very large uncertainties, made greater by the need to group compounds into surrogates.

\subsection{Effects on partitioning}

The impact of uncertainties in the vapour pressures on gas/aerosol partitioning depends on a number of factors: the activity coefficients of the organic species in the aerosol liquid phase (since $p_{i}=x_{i} f_{i} p_{i}^{o}$ ), the total amounts of the organic compounds per $\mathrm{m}^{3}$ of atmosphere, and the amounts of water (for the water-soluble organics) or primary organic material into which the semi-volatile compounds may partition. The principal water soluble surrogate compounds in the UCD-CACM model are A1-5 and B1-2 (see Paper 1), which we attribute to the presence of polar groups $-\mathrm{COOH}$ and $\mathrm{OH}$. We have investigated the effects of uncertainties in $p^{\circ}$ for these compounds by calculating their equilibrium partitioning, at $25^{\circ} \mathrm{C}$, into aerosol and cloud droplets with liquid water contents ranging from $1 \times 10^{-6}$ to 1.0 grams of liquid water per $\mathrm{m}^{3}$ of atmosphere. Starting from the equilibrium relationship above, we can write:

$$
\begin{aligned}
& n_{g}=x_{i} f_{i} p_{i}^{\circ}(273.15 / T)(1 / 0.022414) \\
& =\left[n_{a} /\left(g_{w} / M_{w}+n_{a}\right)\right] f_{i} p_{i}^{\circ}(273.15 / T)(1 / 0.022414)
\end{aligned}
$$

where $n_{g}$ is the number of moles of gas $i$ in the vapour phase at equilibrium, $n_{a}$ is the number of moles of $i$ in the aerosol phase, $g_{w}\left(\mathrm{~g} \mathrm{~m}^{-3}\right)$ is the amount of liquid water in the aerosol phase, $M_{w}\left(18.0152 \mathrm{~g} \mathrm{~mol}^{-1}\right)$ is the molar mass of water, $T$ $(\mathrm{K})$ is the ambient temperature and $0.022414 \mathrm{~m}^{3} \mathrm{~mol}^{-1}$ is the molar volume of an ideal gas at standard temperature and pressure $(273.15 \mathrm{~K})$. Equation (1b) was solved to obtain $n_{a}$ and $n_{g}$ for fixed total amounts of organic solute $\left(n_{T}\right.$, equal to $n_{a}+n_{g}$ ). For the case where the amount of organic solute in the aerosol, $n_{a}$, is much less than $g_{w} / M_{w}$, then the following equation for the partitioning can be written:

$$
\begin{aligned}
& n_{a} / n_{T}=1 /\left[1+\left(M_{w} / g_{w}\right) f_{i} p_{i}^{\circ}(273.15 / T)(1 / 0.022414)\right](2 \mathrm{a}) \\
& =1 /\left[1+803.75 f_{i}\left(p_{i}^{\circ} / g_{w}\right)(273.15 / T)\right]
\end{aligned}
$$

where $n_{a} / n_{T}$ is the fraction of the total amount of organic material per $\mathrm{m}^{3}$ that is present in the aerosol or cloud droplet liquid phase at equilibrium. In these calculations we have used the total amounts $\left(n_{T}\right)$ of each compound listed in Table 1 of Griffin et al. (2003). Values range from $0.1 \mu \mathrm{g} \mathrm{m}^{-3}\left(4.6 \times 10^{-10} \mathrm{~mol} \mathrm{~m}^{-3}\right)$ for $\mathrm{B} 5$, to $5.5 \mu \mathrm{g} \mathrm{m}^{-3}$ $\left(1.8 \times 10^{-8} \mathrm{~mol} \mathrm{~m}^{-3}\right)$ for $\mathrm{B} 4$, and in most cases the approximate Eqs. $(2 \mathrm{a}, \mathrm{b})$ apply even at low RH (the smallest values of $\left.g_{w} / M_{w}\right)$. 

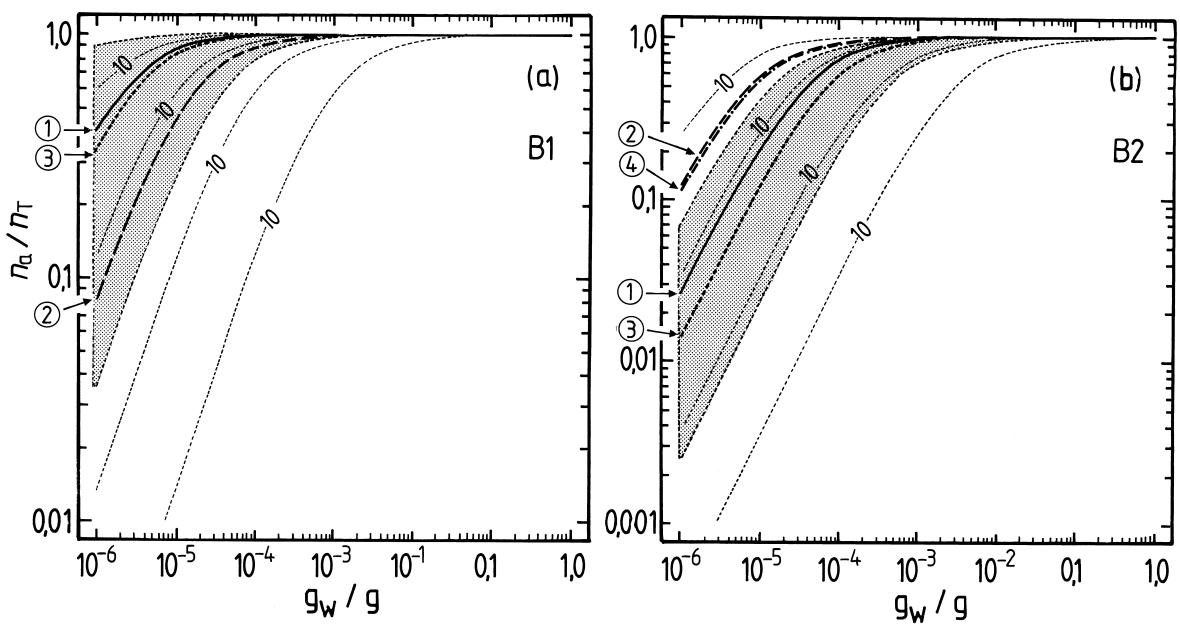

Fig. 4. Fractions of the water-soluble semi-volatile surrogate compounds B1 and B2 present in the aerosol phase at $298.15 \mathrm{~K}$, calculated using Eq. (2a) for different estimates of $p_{i}^{\circ}$, and plotted against atmospheric liquid water content $g_{w}\left(\mathrm{~g} \mathrm{~m}^{-3}\right)$. Unit activity coefficients are assumed. The thin dashed lines represent the calculated partitioning at intervals of factors of 10 in $f_{i} p_{i}^{\circ}$. Vapour pressure estimates, Table 7 , were obtained using the equation of Myrdal and Yalkowsky (1997) together with boiling points estimated by the following methods: 1 value used in UCD-CACM model, without adjustment (solid line); 2 - Nannoolal et al. (2004) (dashed line); 3 - ACD software (dotted line); 4 - a direct prediction of vapour pressure using the method of Asher (Asher and Pankow, 2006; Asher et al., 2002) (dash-dot line). The shaded area corresponds to vapour pressures calculated using the ACD boiling point, plus/minus its estimated uncertainty which is listed in Table 3. (a) Surrogate compound B1; (b) surrogate compound B2.

The results of the partitioning calculations are shown in Fig. 3 for the water soluble surrogate compounds, based upon the adjusted vapour pressures used in the UCD-CACM model. Below the $\mathrm{x}$-axis of plot (b) the amounts of liquid water that are typical of aerosols, clouds, and fogs are indicated. In the aerosol region, $\left(g_{w}<1 \times 10^{-4} \mathrm{~g} \mathrm{H}_{2} \mathrm{O} \mathrm{m}^{-3}\right)$, the equivalent $\mathrm{RH}$ above an acid ammonium sulphate aerosol is marked, based upon a rough $1 \times 10^{-4} \mathrm{~g} \mathrm{~m}^{-3}$ of liquid water for an urban environment at $90 \% \mathrm{RH}$. The partitioning calculations were carried out assuming $f_{i}=1.0$ (Raoult's law). However, the results of other calculations of $f_{i}$ using UNIFAC which are discussed in Paper 1 suggest that actual values are much greater than this, in some cases by orders of magnitude. (Recall that these activity coefficients are for a reference state of the pure subcooled organic compound. Consequently values for dilute solutions in water are generally very different from unity.) The contours on each graph represent the calculated $n_{a} / n_{T}$ for values of $f_{i} p_{i}^{\circ}$ at logarithmic intervals of $\times 10$. The effect of $f_{i}$ different from unity can be estimated for any plotted partitioning curve from these contours. For example, the calculated value of the activity coefficient $\left(f_{i}\right)$ of $\mathrm{A} 2$ in aqueous solution is typically about 13 (Table 2 of Paper 1), which would reduce the fraction of $\mathrm{A} 2$ in the aerosol phase from about 0.8 to less than 0.2 for an atmospheric liquid water content of $10^{-6} \mathrm{~g} \mathrm{~m}^{-3}$ (Fig. 3b).
The results of the partitioning calculations for the water soluble surrogates, for different estimates of $p^{\circ}$, are shown in Figs. 4 and 5. For liquid water contents of $>10^{-3} \mathrm{~g} \mathrm{~m}^{-3}$ all surrogates A, except perhaps A5, can be expected to be in the condensed phase. Above $0.01 \mathrm{~g} \mathrm{~m}^{-3}$ of water the partitioning is essentially complete for all water-soluble compounds. However, for aerosol liquid water contents of $10^{-4} \mathrm{~g} \mathrm{~m}^{-3}$ and below, the differences in partitioning associated with the uncertainties for each estimated $p^{\circ}$ are large. For example, even at $90 \% \mathrm{RH}$ the differences between $p^{\circ}$ for A3 obtained with the upper and lower limits of the boiling point estimated using the ACD method lead to $n_{a} / n_{T}$ ranging from 0.006 to almost 0.4. No compounds except A2 and perhaps B1 are predicted to be mostly in the aerosol phase at moderate to low RH. As is shown in the atmospheric trajectory calculations in Paper 1, most of the secondary organic material is A2, in large part because its value of $p^{\circ}$ implies that most A2 will be in the aerosol phase even at low RH (Fig. 5b). However, the figure also suggests that there is a large uncertainty associated with this $p^{\circ}$ estimate and a higher value still within the possible range - could result in significantly lower partitioning into the aerosol phase.

Based upon the summary of activity coefficients in Table 2 of Paper 1 for a trajectory calculation using the UCDCACM model, the effects of non-ideality are greatest for B2, B1 and A5, for which activity coefficients range from about 2485 (B2) to 131 (B1). Taking these values as typical, assuming an $\mathrm{RH}$ of $80 \%$, and taking into account adjustment factors of 1.4 (B2) and 1.5 (B1) (Griffin et al., 

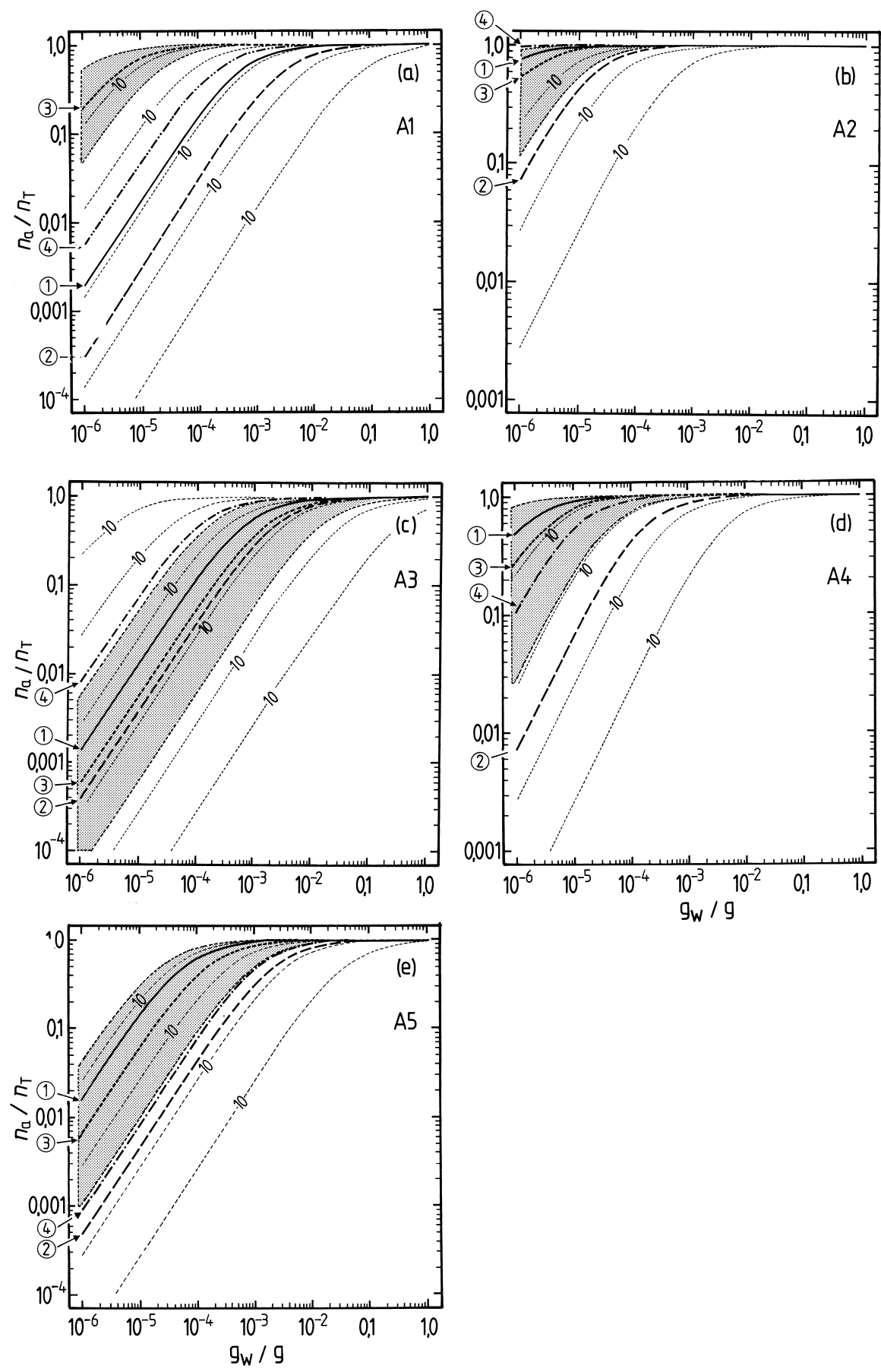

Fig. 5. Fractions of the water-soluble semi-volatile surrogate compounds A1 to A5 present in the aerosol phase at $298.15 \mathrm{~K}$, calculated using Eq. (2a) for different estimates of $p_{i}^{\circ}$, and plotted against atmospheric liquid water content $g_{w}\left(\mathrm{~g} \mathrm{~m}^{-3}\right)$. Unit activity coefficients are assumed. The thin dashed lines represent the calculated partitioning at intervals of factors of 10 in $f_{i} p_{i}^{\circ}$. Vapour pressure estimates, Table 6 , were obtained using the equation of Myrdal and Yalkowsky (1997) together with boiling points estimated by the following methods: 1 value used in UCD-CACM model, without adjustment (solid line); 2 - Nannoolal et al. (2004) (dashed line); 3 - ACD software (dotted line); 4 - a direct prediction of vapour pressure using the method of Asher (Asher and Pankow, 2006; Asher et al., 2002) (dash-dot line). The shaded area corresponds to vapour pressures calculated using the ACD boiling point, plus/minus its estimated uncertainty which is listed in Table 3. (a) Surrogate compound A1; (b) A2; (c) A3; (d) A4; (e) A5. 
2005), the calculated partitioning of these compounds would change from $n_{a} / n_{T} \approx 50 \%$ to $n_{a} / n_{T}<0.1 \%$ for $\mathrm{B} 2$ and from $n_{a} / n_{T} \approx 90 \%$ to $n_{a} / n_{T} \approx 20 \%$ for B1 in Figs. $4 \mathrm{a}, \mathrm{b}$. These rough calculations are based upon the plotted lines for the values of the vapour pressures used in the UCD-CACM model (marked "1" on the figure) and the contours which indicate the effects of factor of 10 variations in $f_{i} p_{i}^{\circ}$. In the trajectory calculation in Paper 1 the total aerosol liquid water at 80\% RH and between 04:00 a.m. and 08:00 a.m. is about $13 \times 10^{-6} \mathrm{~g} \mathrm{~m}^{-3}$, and $n_{a} / n_{T}$ for B1 and B2 are 0.24 and $5 \times 10^{-4}$, respectively. These values are broadly consistent with those obtained from Fig. 4 as long as the activity coefficients are taken into account. For A2, the dominant organic surrogate and for which the activity coefficient $f_{i}$ in the trajectory calculations is only about 13 (Table 2 of Paper 1), $n_{a} / n_{T}$ is about 0.88 in the calculation, for the same water content, which is also consistent with the calculated partitioning shown in Fig. 5b.

A further feature of the plots in Figs. 4 and 5 worth noting is that $\log _{10}\left(n_{a} / n_{T}\right)$ decreases monotonically as $\log _{10}\left(g_{w}\right)$ decreases. However, at zero $\mathrm{RH}, n_{a} / n_{T}$ will have a small positive value if the total amount of organic compound present $\left(n_{T}\right)$ exceeds $\left(p^{\circ} / 0.022414\right)(273.15 / T)$, otherwise $n_{a} / n_{T}$ will be zero. In the atmosphere it is found that even at very low $\mathrm{RH}$, for which aerosols contain negligible amounts of water, considerable amounts of SOA tend to remain. Probable reasons for this include chemical reactions in the aerosol that create compounds and oligomers that are essentially involatile. In the UCD-CACM model the effects of such reactions, still little known, are approximated by decreasing the subcooled liquid vapour pressures of some surrogate compounds, as noted earlier. The effect of this is to shift the curves in Figs. 4 and 5 upwards.

The conclusion to be drawn from these calculations is that the uncertainties in the estimated $p^{\circ}$ of the organic surrogates are large, and their effects on partitioning are significant for RH below 80-90\%. Furthermore, given that most of the SOA compounds are polar and multifunctional, and because of the limitations of current predictive methods, these uncertainties seem likely to remain even as SOA composition becomes better known.

We have not carried out calculations for the partitioning of the non-water-soluble SOA species B3 to B5. These are expected to behave differently from the water soluble compounds in one important respect: there should be no variation of $n_{a} / n_{T}$ with RH, but rather with the total amount of organic material in the aerosol - which is largely P8 in the simulations carried out in Paper 1.

\section{Summary}

The physical properties of polar multifunctional organic compounds, such as those that make up SOA, are among the most difficult to predict. The variations between the pre- dicted boiling points and vapour pressures of the eighteen compounds considered here are significantly greater than would be expected from the uncertainty analyses presented in the papers describing the different methods used. This appears to be because those comparisons are mainly based upon data for monofunctional compounds for which group contribution methods work best.

The boiling point methods that yield predictions that agree most closely are those of Nannoolal et al. (2004) which is a refinement of the approach of Cordes and Rarey (2002), the ACD method, and that of Stein and Brown (1994). Cordes and Rarey (2002) have shown that their method, also used by Nannoolal et al. (2004), is significantly more accurate than those of Stein and Brown (1994) and Constantinou and Gani (1994) for a test set of 1863 components. The ACD approach tends to yield higher values of $T_{b}$ for the oxygenated SOAforming surrogate compounds than the other methods, but not for the primary surrogate compounds P1-8. Of the methods examined in this study those of Nannoolal et al. (2004) and ACD are likely to be most accurate. However, Cordes and Rarey (2002) caution that results obtained with all group contribution methods for molecules with large numbers of functional groups should be used only with great care, as they are subject to a large uncertainty.

The ACD predictor provides estimates of the errors associated with each calculated value of $T_{b}$. These are larger than the average absolute deviations provided by the DDBST software, and also greater than the uncertainties associated with each method as assessed by the authors. However, the comparisons shown in Figs. 1 and 2 suggest that the ACD error estimates are the most realistic. If they are assumed to apply to each of the preferred boiling point methods referred to above, the predictions of these methods can be said to be consistent. The average absolute deviations in $T_{b}$ given by the DDBST software, for each compound class to the molecule of interest belongs, are likely to be more reliable estimates of uncertainty than the values given in the papers describing the methods (and summarised in the Appendix), because they are based upon comparisons against all the boiling point data in the Dortmund Data Bank and are therefore much more broadly based. However, the results shown in Figs. 1 and 2 suggest that these estimates are still too low for the multifunctional compounds studied here.

Vapour pressures at $298.15 \mathrm{~K}$, calculated using predicted $T_{b}$ and the Myrdal and Yalkowsky (1997) equation, the UNIFAC-based approach of Asher (Asher and Pankow, 2006; Asher et al., 2002), and the method of Nannoolal (2007), cover orders of magnitude for some of the compounds studied here (see Tables 5 to 7). The UNIFAC based approach yields the lowest $p^{\circ}$ for the primary surrogate compounds, and also the largest $\Delta H_{\text {vap. }}^{o}$. Although enthalpies of vaporisation have not been discussed in this work, we note that values obtained using the UNIFAC-based method appear to be too high when compared with data for organic compounds of similar molar mass (from the DIPPR 


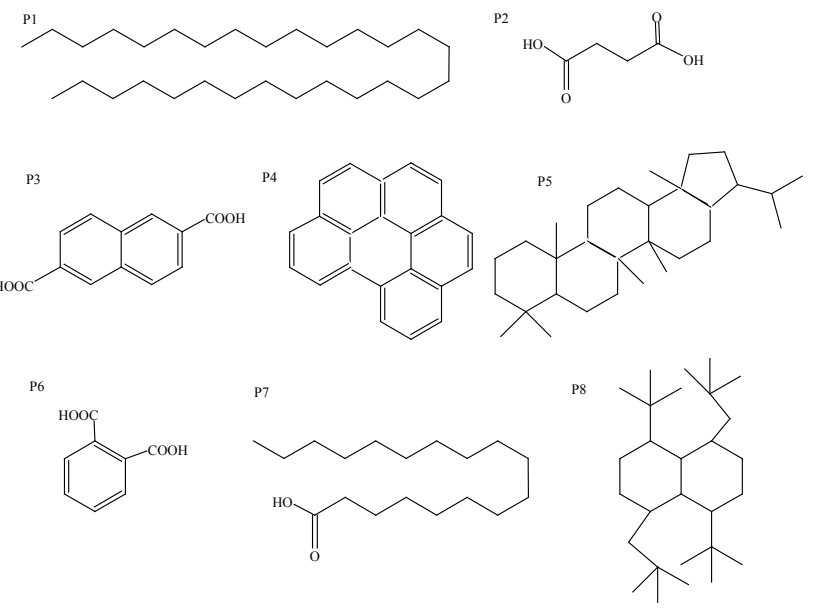

Fig. 6. Structures of the eight surrogate species for primary organic material (POA).

Thermophysical Database). This is consistent with predictions of $p^{\circ}$ that are too low.

Experimentally based values of $p^{\circ}$ are available for surrogate compounds P2 (succinic acid), P4 (benzo[ghi]perylene), and A1 (oxalic acid). In each case the vapour pressures calculated using the Myrdal and Yalkowsky equation (and $T_{b}$ from the Nannoolal et al. (2002) and ACD methods), and the Nannoolal (2007) model, agree to within about a factor of ten. However, these three compounds are not representative of the range of potential semi-volatile organic compounds in the atmosphere, and further studies focusing on experimental data for multifunctional compounds are necessary.

The differences between the values of $p^{\circ}$ obtained using the methods studied here establish only an approximate uncertainty for the predictions. It is encouraging that the group of boiling point methods that have the lowest uncertainties (as assessed by the DDBST software, and shown as error bars in Figs. 1 and 2) yield predictions that agree most closely. However, the analogous agreement in $p^{\circ}$ may be misleading because all of the predictive methods for vapour pressure except that of Asher are based upon boiling points. The Myrdal and Yalkowsky equation should be assessed independently using multi-functional compounds for which both boiling point and vapour pressure data are available.

Calculations of gas/aerosol partitioning of those semivolatile surrogate compounds predicted to be water soluble (Paper 1) are shown in Figs. 4 and 5 as a function of atmospheric liquid water content. The results indicate that both the uncertainty associated with each $p^{\circ}$ prediction, and the range of $p^{\circ}$ obtained with the different methods, imply large effects on partitioning at moderate to low $\mathrm{RH}$ - particularly for B1, A1, A2, A4 and A5. It seems likely that this will be true of other atmospheric organic compounds of similar functionality. Calculations presented in Paper 1 suggest that the activity coefficients $f_{i}$ of many of the water-soluble sur-
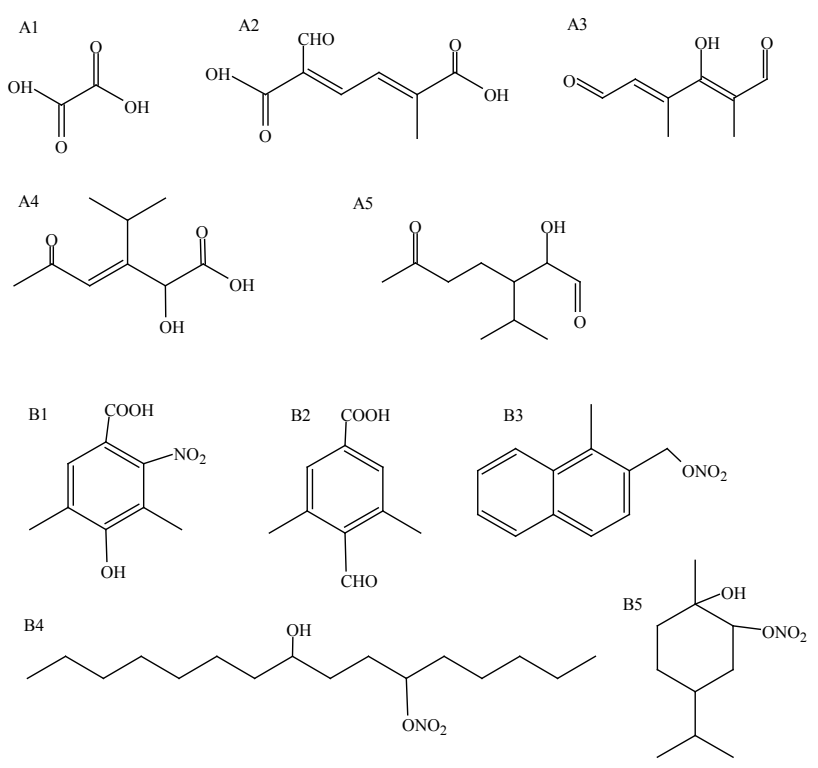

Fig. 7. Structures of the ten surrogate species for secondary organic material (SOA). Note that B5 has been corrected, and differs from the structure given by Griffin et al. (2003).

rogate compounds have large values (ranging from about 1.0 for A1 to 2000 for B2 in water) and that these must taken into account when calculating equilibrium partitioning. (Values of $f_{i}$ greater than unity reduce the equilibrium partitioning of the compound into the aerosol.)

Experimental values of $p^{\circ}$ for butane and $\mathrm{C} 4$ alcohols and carboxylic acids shown in Table 1 demonstrate that $p^{\circ}$ is very sensitive to the type and number of functional groups present, and their position(s) on the molecule. For this reason the use of surrogate compounds to represent large numbers of semivolatile reaction products in atmospheric models is a considerable approximation, because each surrogate may represent a set of compounds with vapour pressures varying over orders of magnitude (Table 8). This and other problems related to the vapour pressures and activity coefficients of organic compounds, and their inclusion in the UCD-CACM model, are discussed in Paper 1.

\section{Appendix A}

The structures of the 18 compounds in the UCD-CACM model are shown in Figs. 6 and 7. Apart from a correction to the structure of B5 (see Paper 1), they are the same as shown by Griffin et al. (2003).

The vapour pressures of the surrogate compounds estimated using the Myrdal and Yalkowsky (1997) equation, and listed in Tables 5-7, require boiling points at atmospheric pressure, a structural parameter $\tau$, and a hydrogen bonding number HBN. In earlier versions of the UCD-CACM model there were some errors in these parameters. The correct 
Table 9. Molecular parameters of the surrogate compounds.

\begin{tabular}{llllll}
\hline Surrogate & $\tau$ & HBN & Surrogate & $\tau$ & HBN \\
\hline B1 & 0 & 0.00670 & P1 & 26.0 & 0 \\
B2 & 0 & 0.00561 & P2 & 2.0 & 0.012 \\
B3 & 2.0 & 0 & P3 & 0.5 & 0.00654 \\
B4 & 14.5 & 0.00330 & P4 & 0 & 0 \\
B5 & 1.5 & 0.00461 & P5 & 0.5 & 0 \\
A1 & 0 & 0.0157 & P6 & 0.5 & 0.00851 \\
A2 & 2.5 & 0.00768 & P7 & 15.5 & 0.00351 \\
A3 & 2.0 & 0.00649 & P8 & 5.5 & 0 \\
A4 & 3.0 & 0.00759 & & & \\
A5 & 5.0 & 0.00537 & & & \\
\hline
\end{tabular}

Notes: see Myrdal and Yalkowsky (1997), and references therein, for a description of the parameters and how to determine them from the structure of the molecule.

values are listed in Table 9. The characteristics of the boiling point estimation methods used in this work are summarised below.

Joback and Reid (1987) correlated the normal boiling point, $T_{b}$, of organic compounds containing the elements $\mathrm{C}$, $\mathrm{H}, \mathrm{O}, \mathrm{N}, \mathrm{S}$ and the halogens according to: $T_{b}=198.2+\Sigma_{i} n_{i} g_{i}$ where $g_{i}$ (equal to $\Delta T_{b(i)}$ ) is the increment value of group $i$ and $n_{i}$ is the number of times the group occurs in the compound. Joback and Reid employed a set of 41 groups, and a database of 438 compounds, and their equation fitted the data with an average absolute error of $12.9 \mathrm{~K}$ and a $3.6 \%$ average error. Stein and Brown (1994) adopted the same approach, but used a much larger dataset of 4426 experimental boiling points and increased the number of structural groups to 81 . Predictions of $T_{b}$ of 6584 compounds not used to develop the model yielded an average absolute error of $20.4 \mathrm{~K}$ and a $4.3 \%$ average error, compared to a $15.5 \mathrm{~K}$ absolute error and $3.2 \%$ average error for the points that were fitted.

We note that Devotta and Rao (1992) have also modified the Joback and Reid method, mainly to improve the representation of boiling points of halogenated compounds. For the $\mathrm{C}, \mathrm{H}, \mathrm{O}, \mathrm{N}$ compounds of interest here the method yields essentially the same values as that of Joback and Reid, and is not considered further.

The model of Constantinou and Gani (1994) is a group contribution approach using sets of both first order and second order functional groups. The latter provide more structural information about portions of the molecules which contain interacting groups, for which the first order group definitions alone were found to be insufficient. The accuracy of boiling predictions is given by the authors as an average absolute deviation of $5.35 \mathrm{~K}$, compared to $12.9 \mathrm{~K}$ for the Joback and Reid method. This result is not broken down by organic compound class.

Marrero-Morejon and Pardillo-Fontdevila (1999) have implemented a group interaction approach to predicting $T_{b}$ and critical properties. The authors selected a set of 39 structural groups - essentially the same set as Joback and Reid (1997), and then determined interaction values for pairs of groups by fitting to compiled property values for 507 pure compounds. Average absolute errors in $T_{b}$, for a test set of 98 compounds, was $5.22 \mathrm{~K}$ for the group interaction method, compared to $11.01 \mathrm{~K}$ for a simple group contribution approach analogous to that of Joback and Reid (1987). The authors note, however, that the method is relatively poor for alcohols, phenols and large heterocyclic compounds and for polyhydroxy alcohols (in common with most other models).

Wen and Qiang (2002a) have developed a group vector space (GVS) method to predict the melting and boiling points of compounds. This method, in which the structure of the hydrocarbon molecule is expressed in terms of the groups defined by Joback and Reid (1987) and three topological graphs, is able to take into account functional group position without greatly increasing the number of model parameters or sub-groups. For a set of eight randomly selected test compounds the average percentage deviation in the predicted $T_{b}$ was $0.74 \%$ compared to $2.4 \%$ for the Joback and Reid method. The method was later extended to include $\mathrm{O}$, N, and S compounds (Wen and Qiang, 2002b), again based upon group definitions of Joback and Reid. Average absolute deviations in $T_{b}$ range from about $10.6 \mathrm{~K}$ for aromatic hydrocarbons to $5.7 \mathrm{~K}$ for oxygenated compounds and $3.36 \mathrm{~K}$ for aliphatic hydrocarbons. Comparisons in their Table 3 suggest that average absolute errors are about $1 / 2$ of those obtained using the Joback and Reid method, and comparable with the methods of Constantinou and Gani (1994) and Marrero-Morejon and Pardillo-Fontdevila (1999).

The group contribution method of Cordes and Rarey (2002), which includes second order effects based upon the chemical neighborhood of each structural group, was fitted to data for 2500 compounds. In their Table 5, Cordes and Rarey compare mean absolute deviations between measured and predicted $T_{b}$ for 126 hydrocarbon compounds not included in the database. Values are generally comparable to, or lower than, other methods and the approach appears to be successful over a wider range of compounds. Results are similar for comparisons involving alkanols, oxygenated hydrocarbons, and halogenated hydrocarbons (their Tables 6 to 8, respectively). The work of Nannoolal et al. (2004) is a refinement of the Cordes and Rarey (2002) model, involving some further structural groups, a steric parameter, and the removal of some erroneous values from the database. Nannoolal et al. compare the results of their model with six others in their Tables 6, 7, and 11-14. This method, together with the ACD prediction software, is the primary one used here.

The ACD method is based upon the use of a function of boiling point which is linear, and additive with respect to other molar properties (Kolovanov and Petrauskas, undated). In comparisons with over 6000 boiling points (not broken down by compound class) it was found that predictions were usually within $5 \mathrm{~K}$ of the true values, though the 
largest deviations (only for a very few compounds) were as much as $45 \mathrm{~K}$. The ACD method also yields an expected error as a part of the prediction. It is used by the Chemical Abstracts service of the American Chemical Society to provide estimated boiling points when no experimental values are available. The errors in ACD predictions are typically about one third of those obtained using the method of Joback and Reid (1987), suggesting an accuracy comparable to the model of Nannoolal et al. (2004).

Acknowledgements. This research was supported by U.S. Environmental Protection Agency grant RD-831082 and Cooperative Agreement CR-831194001, by the Natural Environment Research Council of the U.K. (as a part of the Tropospheric Organic Chemistry Experiment, TORCH) and by the European Commission as part of EUCAARI (European Integrated Project on Aerosol Cloud, Climate and Air Quality Interactions). The work has not been subject to the U.S. EPA's peer and policy review, and does not necessarily reflect the views of the Agency and no official endorsement should be inferred. The authors would like to thank the Atmospheric Sciences Modelling Division (ASMD) of U.S. EPA for hosting S. L. Clegg while carrying out this study, and P. Bhave and other ASMD members for helpful discussions.

Edited by: R. Cohen

\section{References}

Asher, W. E. and Pankow, J. F.: Vapour pressure prediction for alkenoic and aromatic organic compounds by a UNIFAC-based group contribution method, Atmos. Environ., 40, 3588-3600, 2006.

Asher, W. E., Pankow, J. F., Erdakos, G. B., and Seinfeld, J. H.: Estimating the vapour pressures of multi-functional oxygencontaining organic compounds using group contribution methods, Atmos. Environ., 36, 1483-1498, 2002.

Camredon, M. and Aumont, B.: Assessment of vapour pressure estimation methods for secondary organic aerosol modeling, Atmos. Environ., 40, 2105-2116, 2006.

Clegg, S. L., Brimblecombe, P., and Khan, I.: The Henry's law constant of oxalic acid and its partitioning into the atmospheric aerosol, Idojaras, 100, 51-68, 1996.

Clegg, S. L., Kleeman, M. J., Griffin, R. J., and Seinfeld, J. H.: Effects of uncertainties in the thermodynamic properties of aerosol components in an air quality model - Part 1: Treatment of inorganic electrolytes and organic compounds in the condensed phase, Atmos. Chem. Phys., 8, 1057-1085, 2008, http://www.atmos-chem-phys.net/8/1057/2008/.

Clegg, S. L. and Seinfeld, J. H.: Thermodynamic models of aqueous solutions containing inorganic electrolytes and dicarboxylic acids at 298.15 K. II. Systems including dissociation equilibria, J. Phys. Chem. A, 110, 5718-5734, 2006.

Constantinou, L. and Gani, R.: New group contribution method for estimating properties of pure compounds, AIChE J., 40, 16971710, 1994.

Cordes, W. and Rarey, J.: A new method for the estimation of the normal boiling point of nonelectrolyte organic compounds, Fluid Phase Equilibria, 201, 409-433, 2002.
Devotta, S. and Rao, P. V.: Modified Joback group contribution method for normal boiling point of aliphatic halogenated compounds, Ind. Eng. Chem. Res., 31, 2042-2046, 1992.

Fraser, M. P., Cass, G. R., Simoneit, B. R. T., and Rasmussen, R. A.: Air quality model evaluation data for organics. 4. $C_{2}-C_{36}$ nonaromatic hydrocarbons, Environ. Sci. Technol., 31, 2356-2367, 1997.

Fraser, M. P., Cass, G. R., Simoneit, B. R. T., and Rasmussen, R. A.: Air quality model evaluation data for organics. 5. $C_{6}-C_{22}$ nonpolar and semipolar aromatic compounds, Environ. Sci. Technol., 32, 1760-1770, 1998.

Griffin, R. J., Dabdub, D., and Seinfeld, J. H.: Secondary organic aerosol - 1. Atmospheric chemical mechanism for production of molecular constituents, J. Geophys. Res., 107(D17), 4332, doi:10.1029/2001JD000541, 2002.

Griffin, R. J., Dabdub, D., and Seinfeld, J. H.: Development and initial evaluation of a dynamic species-resolved model for gas phase chemistry and size-resolved gas/particle partitioning associated with secondary organic aerosol formation, J. Geophys. Res., 110(D5), 05304, doi:10.1029/2004JD005219, 2005.

Griffin, R. J., Nguyen, K., Dabdub, D., and Seinfeld, J. H.: A coupled hydrophobic-hydrophilic model for predicting secondary organic aerosol formation, J. Atmos. Chem., 44, 171-190, 2003.

Jaoui, M., Kleindienst, T. E., Lewandowski, M., Offenburg, J. H., and Edney, E. O.: Identification and quantification of aerosol polar oxygenated compounds bearing carboxylic or hydroxyl groups. 2. Organic tracer compounds from monoterpenes, Environ. Sci. Technol., 39, 5661-5673, 2005.

Joback, K. G. and Reid, R. C.: Estimation of pure component properties from group contributions, Chem. Eng. Commun., 57, 233243, 1987.

Kleeman, M. J., Hughes, L. S., Allen, J. O., and Cass, G. R.: Source contributions to the size and composition distribution of atmospheric particles: Southern California in September, 1996, Environ. Sci. Technol., 33, 4331-4341, 1999.

Lei, Y. D., Chankalal, R., Cahn, A., and Wania, F.: Supercooled liquid vapour pressures of the polycyclic aromatic hydrocarbons, J. Chem. Eng. Data, 47, 801-806, 2002.

Marrero-Morejon, J. and Pardillo-Fontdevila, E.: Estimation of pure compound properties using group-interaction contributions, AIChE J., 45, 615-621, 1999.

Myrdal, P. B. and Yalkowsky, S. H.: Estimating pure component vapour pressures of complex organic molecules, Ind. Eng. Chem. Res., 36, 2494-2499, 1997.

Nannoolal, Y.: Development and critical evaluation of group contribution methods for the estimation of critical properties, liquid vapour pressure and liquid viscosity of organic compounds, Ph.D Thesis, University of Kwazulu-Natal, 2007.

Nannoolal, Y., Rarey, J., Cordes, W., and Ramjugernath, D.: Estimation of pure component properties: Part 1. Estimation of the normal boiling point of non-electrolyte organic compounds via group contributions and group interactions, Fluid Phase Equilibria, 226, 45-63, 2004.

Peng, C., Chan, M. N., and Chan, C. K.: The hydgroscopic properties of dicarboxylic and multifunctional acids: measurements and UNIFAC predictions, Environ. Sci. Technol., 35, 4495-4501, 2001.

Ribeiro da Silva, M. A. V., Monte, M. J. S., and Ribeiro, J. R.: Thermodynamic study on the sublimation of succinic acid and 
methyl- and dimethyl-substituted succinic and glutaric acids, J. Chem. Thermo., 33, 23-31, 2001.

Sanghvi, R. and Yalkowsky, S. H.: Estimation of heat capacity of boiling of organic compounds, Ind. Eng. Chem. Res., 45, 451453, 2006a.

Sanghvi, R. and Yalkowsky, S. H.: Estimation of normal boiling point of organic compounds, Ind. Eng. Chem. Res., 45, 28562861, 2006b.

Stein, S. E. and Brown, R. L.: Estimation of normal boiling points from group contributions, J. Chem. Inf. Comput. Sci., 34, 581587, 1994.
Wen, X. and Qiang, Y.: Group vector space (GVS) method for estimating boiling and melting points of hydrocarbons, J. Chem. Eng. Data, 47, 286-288, 2002a.

Wen, X. and Qiang, Y.: Group vector space method for estimating boiling and melting points of organic compounds, Ind. Eng. Chem. Res., 41, 5534-5537, 2002b.

Yu, J., Cocker III, D. R., Griffin, R. J., Flagan, R. C., and Seinfeld, J. H.: Gas-phase oxidation of monoterpenes: gaseous and particulate products, J. Atmos. Chem., 34, 207-258, 1999.

Zhao, L., Li, P., and Yalkowsky, S. H.: Predicting the entropy of boiling for organic compounds, J. Chem. Inf. Comput. Sci., 39, 1112-1116, 1999. 